\title{
DAPK1-p53 Interaction Converges Necrotic and Apoptotic Pathways of Ischemic Neuronal Death
}

\author{
Lei Pei, ${ }^{1,5 *}$ You Shang, ${ }^{2,5 *}$ Huijuan Jin, ${ }^{1,5 *}$ Shan Wang, ${ }^{1,5} \mathrm{Na}$ Wei, ${ }^{1,5}$ Honglin Yan, ${ }^{1,5}$ Yan $\mathrm{Wu}^{3,5}$ Chengye Yao, ${ }^{1,5}$ \\ Xiaoxi Wang, ${ }^{1,5}$ Ling-Qiang $\mathrm{Zhu}^{4,5}$ and Youming $\mathrm{Lu}^{1,3,5}$ \\ ${ }^{1}$ Department of Physiology, Tongji Medical College, Huazhong University of Science and Technology, Wuhan, 430030, China, ${ }^{2}$ Department of \\ Anesthesiology, Union Hospital, Tongji Medical College, Huazhong University of Science and Technology, Wuhan, 430030, China, ${ }^{3}$ Department of \\ Neurology, Union Hospital, Tongji Medical College, Huazhong University of Science and Technology, Wuhan, 430030, China, ${ }^{4}$ Department of \\ Pathophysiology, Tongji Medical College, Huazhong University of Science and Technology, Wuhan, 430030, China, and ${ }^{5}$ Institute of Brain Research, \\ Huazhong University of Science and Technology, Wuhan, 430030, China
}

Necrosis and apoptosis are two distinct types of mechanisms that mediate ischemic injury. But a signaling point of convergence between them has yet to be identified. Here, we show that activated death-associated protein kinase 1 (DAPK1), phosphorylates p53 at serine-23 $\left(p S^{23}\right)$ via a direct binding of DAPK1 death domain (DAPK1DD) to the DNA binding motif of p53 (p53DM). We uncover that the $p S^{23}$ acts as a functional version of $\mathrm{p} 53$ and mediates necrotic and apoptotic neuronal death; in the nucleus, $p \mathrm{~S}^{23}$ induces the expression of proapoptotic genes, such as $B a x$, whereas in the mitochondrial matrix, $p S^{23}$ triggers necrosis via interaction with cyclophilin D (CypD) in cultured cortical neurons from mice. Deletion of DAPK1DD (DAPK1 ${ }^{\mathrm{DD} \Delta}$ ) or application of Tat-p53DM that interrupts DAPK1-p53 interaction blocks these dual pathways of $p \mathrm{~S}^{23}$ actions in mouse cortical neurons. Thus, the DAPK1-p53 interaction is a signaling point of convergence of necrotic and apoptotic pathways and is a desirable target for the treatment of ischemic insults.

Key words: DAPK1; ischemia; neuronal death; NMDA receptors

\section{Introduction}

In ischemia, lack of oxygen and glucose depletes the cellular energy and hence causes a wide range of deleterious cellular reactions (Lipton, 1999; Moskowitz et al., 2010). These include loss of ionic homeostasis, production of reactive oxygen species (Lipton, 1999; Aarts et al., 2002; Brennan et al., 2009), production of reactive nitrogen species (Aarts et al., 2002), and mitochondrial dysfunctions (Schinzel et al., 2005; Cheung et al., 2007; Vaseva et al., 2012). As a consequence, cells die via necrosis (i.e., swelling, rupture and cytolysis), apoptosis (i.e., chromatin condensation and DNA breaks), or both, depending in part upon the cell types in the brain (Chan, 2001; Yuan, 2009). However, whether there is a "core signaling program" that controls these two distinct types of cell death pathways needs to be determined.

\footnotetext{
Received Dec. 8, 2013; revised March 26, 2014; accepted March 30, 2014.

Author contributions: L.P., Y.S., Y.W., L.-Q.Z., and Y.L. designed research; L.P., Y.S., H.J., X.W., S.W., N.W., H.Y., and Y.L. performed research; L.P., Y.S., H.J., X.W., S.W., N.W., H.Y., Y.W., L.-Q.Z., and Y.L. analyzed data; L.P., Y.S., H.J., Y.W., L.-Q.Z., and Y.L. wrote the paper.

This work was supported by National Natural Science Foundation of China Grants 81130079 and 91232302 to Y.L., 81200863 to L.P., 81271270 to Y.S., and 81361120245 and Ministry of Science and Technology of China Grant 2011DFG33250 to L.-Q.Z. We thank Ruojian Wen (Huazhong University of Science and Technology) for cell cultures, Kunpeng Zhao (Huazhong University of Science and Technology) for cell death assays and real-time PCR, and Qing Tian for comments on the manuscript.

The authors declare no competing financial interests.

*L.P., Y.S., and H.J. contributed equally to this work.

Correspondence should be addressed to either Dr. Ling-Qiang Zhu or Youming Lu, Department of Physiology, Tongji Medical College, Huazhong University of Science and Technology, Wuhan, 430030, China, E-mail: zhulq@hust.edu.cn or lym@hust.edu.cn.

DOI:10.1523/JNEUROSCI.5119-13.2014

Copyright $\odot 2014$ the authors $\quad 0270-6474 / 14 / 346546-11 \$ 15.00 / 0$
}

Necrosis and apoptosis are activated during ischemic injuries through multiple cellular pathways, such as $\mathrm{Ca}^{2+}$ overloading and reactive oxygen species/reactive nitrogen species production (Lipton, 1999; Lo et al., 2005; Yuan, 2009; Moskowitz et al., 2010), and are involved in an excessive stimulation of glutamate transmitter receptors (Lipton and Rosenberg, 1994; Hardingham and Bading, 2010; Moskowitz et al., 2010). However, these receptors also function physiologically in the regulation of gene expression, plasticity, and neuronal survival and hence are not desirable targets in ischemic neuronal death (Ginsberg, 2009). We recently reported that death-associated protein kinase 1 (DAPK1) constitutes a specific cell death signaling molecule that is directly linked to glutamate receptor channels (Tu et al., 2010). DAPK1 is a newly identified $\mathrm{Ca}^{2+} /$ calmodulin-dependent protein kinase (Bialik and Kimchi, 2006) and plays a role in several modes of cell death, including apoptosis and autophagy (Raveh et al., 2000; Van Eldik, 2002). However, downstream signaling of DAPK1 that specifically mediates ischemic injuries remains unknown.

Here, we identified a direct binding of the DAPK1 death domain (DAPK1DD) to the DNA binding motif (DM) of the tumor suppressor protein p53 (p53DM). We synthesized a membrane-permeable 5 53DM peptide consisting of amino acid residues $270-281$ (p53DM) that specifically blocks DAPK1DDp53DM binding in mouse cortical neurons. We also devised multiple genetic deletion/rescue experiments in the cultured cortical neurons from mice and demonstrated that an interaction between DAPK1 and p53 is a signaling point of convergence of necrosis and apoptosis in ischemic insults. 


\section{Materials and Methods}

Yeast two-hybrid screen. Yeast two-hybrid analysis was performed using the L40 yeast strain, which carries reporter genes His3 and LacZ under the control of upstream LexA binding sites. A cDNA encoding DAPK1DD (residues 1318-1393) was cloned from full-length DAPK $1^{1-1430}$ (Accession: NP_598823) into $p$ BHA (LexA-DD fusion vector) as bait and VP16 as an activation domain (AD) for screening a mouse brain cDNA library, constructed in pGAD10 (GAL4 activation domain vector, Clontech). A total of $1 \times 10^{7}$ transformants were screened. Colonies on plates lacking histidine (supplemented with $2.5 \mathrm{~mm}$ of 3-aminotriazole) with a blue color with X-gal were selected for plasmid recovery, as described previously (Tu et al., 2010).

Coimmunoprecipitation and GST affinity binding assays. The cerebral cortex from adult male C57BL/6J mice at 4 months old of age was homogenized in ice-cold lysis buffer containing (mM) the following: 50 Tris-HCl, $150 \mathrm{NaCl}, 1 \% \mathrm{NP}-40,2$ EDTA, 1 Na-orthovanadate, $\mathrm{pH}$ 7.4, and proteinase inhibitor mixture $(5 \mu \mathrm{l} / 100 \mathrm{mg}$ tissue, Sigma). After clearing debris by centrifugation at $14,000 \times g$ at $4^{\circ} \mathrm{C}$, protein concentration in the extracts was determined using the Bradford assay (BioRad), as described previously ( $\mathrm{Tu}$ et al., 2010). The nuclear/ mitochondrial fractions were prepared using cell fractionation kits (BioVision), according to the manufacturer's instructions. The extracts (500 $\mu$ g proteins) were incubated with nonspecific IgG (IgG, $2 \mu \mathrm{g}$ ) or polyclonal rabbit anti-DAPK1 $(2 \mu \mathrm{g}$; Thermo Fisher Scientific, catalog \#PA5-17055) or anti-p53 (2 $\mu \mathrm{g}$, Abcam, catalog \#ab26) overnight at $4^{\circ} \mathrm{C}$, followed by the addition of $40 \mu \mathrm{l}$ of Protein G-Sepharose (Sigma) for $3 \mathrm{~h}$ at $4^{\circ} \mathrm{C}$. The precipitates were washed four times with lysis buffer and denatured with SDS sample buffer and separated using 12\% SDS-PAGE. The proteins were transferred onto nitrocellulose membranes using a Bio-Rad mini-protein-III wet transfer unit overnight at $4^{\circ} \mathrm{C}$. Transfer membranes were then incubated with blocking solution $(5 \%$ nonfat dried milk dissolved in TBST buffer containing $10 \mathrm{~mm}$ Tris- $\mathrm{HCl}, 150 \mathrm{~mm}$ $\mathrm{NaCl}$, and $0.1 \%$ Tween- 20 for $1 \mathrm{~h}$ at room temperature, washed three times, and incubated with anti-goat primary antibody against antiDAPK1 (Epitomics, catalog \#3798-1) or anti-p53 (Millipore, catalog \#04-1083) for $1 \mathrm{~h}$ at room temperature. The membranes were washed three times with TBST buffer and incubated with the appropriate secondary antibodies (1:1000 dilution) for $1 \mathrm{~h}$ followed by washing four times. Signal detection was performed using an enhanced chemiluminescence kit (GE Healthcare). The lanes marked "input" were loaded with $10 \%$ of the starting material used for immunoprecipitation.

To determine a binding sequence of DAPK 1 DD with $\mathrm{p} 53$ protein, the GST-p53 deletion mutants (GST-p53 ${ }^{1-61}$, GST-p53 ${ }^{61-126}$, GST-p53 ${ }^{126-241}$, GST-p53 $3^{241-281}$, and GST-p53 ${ }^{281-390}$ ) were generated from full-length cDNA mouse $\mathrm{p} 53^{1-390}$ (Addgene, $p$ LCRcala (p53), plasmid 12136), as we described previously (Tu et al., 2010; Yang et al., 2012). Purified GST fusion proteins were separated using SDS-PAGE and transferred onto a nitrocellulose membrane, which was washed with distilled water and blocked with TBST for $1 \mathrm{~h}$ at room temperature. The membrane was then incubated with affinity binding buffer containing $50 \mathrm{~mm}$ Tris- $\mathrm{HCl}, \mathrm{pH}$ $7.5,200 \mathrm{~mm} \mathrm{NaCl}, 12 \mathrm{~mm} \alpha$-mercaptoethanol, $1.0 \%$ polyethylene glycol, $10 \mu \mathrm{g} / \mathrm{ml}$ protease inhibitors, and $500 \mu \mathrm{g} / \mathrm{ml}$ purified Flag-tagged DAPK1 DD (Invitrogen) for $1 \mathrm{~h}$ at room temperature and washed four times for 5 min with affinity binding buffer. Bound DAPK1DD was detected with anti-Flag (1:2000, Invitrogen).

Luciferase reporter assays. The p53-response luciferase construct that encodes firefly luciferase reporter genes under the control of a minimal $\mathrm{CMV}$ promoter and tandem repeats of the $\mathrm{p} 53$ transcriptional response element was used to study the transcriptional activity of p53 (QIAGEN). cDAPK1, which lacks a calmodulin regulatory domain (amino acids $266-312$ ), and $\mathrm{CDAPK} 1^{\mathrm{DD} \Delta}$ were generated as we described previously (Tu et al., 2010). Cells were transiently cotransfected with the indicated expression plasmids and reporter constructs in HEK293 cells. A pool of three specific 19-25 nt p53 siRNA and the scrambled control (s-siRNA) were purchased from Santa Cruz Biotechnology (sc-29435). At $48 \mathrm{~h}$ after transfection, whole-cell lysates were prepared, and luciferase activity was assessed using the Promega dual luciferase assay system. The firefly luminescence signal was normalized to Renilla luminescence signal. The cell lysates were also prepared and probed with antibodies against p53 and GAPDH.

Cortical cultures and cell death analysis. The male heterozygous mutant mice with a deficiency in the expression of DAPK1 $\left(D A P K 1^{+/-}\right.$mice with the C57BL/6J background) (Tu et al., 2010), p53 ( $p 53^{+/-}$mice with the 129Sv background, The Jackson Laboratory), cyclophilin D $\left(C y p D^{+/-}\right.$mice with the C57BL/6-129 mixed background, The Jackson Laboratory), or Bax gene ( $\mathrm{Bax}^{+/-}$mice with the C57BL/6 background, The Jackson Laboratory) were bred with their respective heterozygous female mice. The cerebral cortex was isolated from the homozygous E20 embryos, including DAPK1 $1^{-1-}, p 53^{-1-}, C y p D^{-1-}$, or $B a x^{-l-}$ and the respective wild-type controls $\left(D A P K 1^{+/+}, p 53^{+/+}, C y p D^{+/+}\right.$, and $B a x^{+/+}$embryos, as described previously) (Tu et al., 2010; Yang et al., 2012). Cells were dissociated and purified using a papain dissociation kit (Worthington Biochemical) plated at a density of $100-150$ cells $/ \mathrm{mm}^{2}$ on $19 \mathrm{~mm}$ coverslips coated with $30 \mu \mathrm{g} / \mathrm{ml}$ poly-D-lysine and $2 \mu \mathrm{g} / \mathrm{ml}$ laminin. The cells were placed in fresh serum-free Neurobasal Medium (21103, Invitrogen) plus 2\% B27, and the medium was replaced every $4 \mathrm{~d}$. Some cultures were stained for $\beta$-tubulin III (Tuj1), a neuronal marker to confirm that these cultures were $>85 \%$ neurons.

On day 10 (DIV10), wDAPK1, cDAPK1, cDAPK1 ${ }^{\mathrm{DD} \Delta}$, wild-type $\mathrm{p} 53$, or mutant $\mathrm{p} 53 \mathrm{~A}^{23}$ was expressed using the respective $\mathrm{rAAV} 1 / 2$ - virus particles by the addition of $1 \mu \mathrm{l}$ of the virus particles $\left(9 \times 10^{12}\right.$ genomic particle $/ \mathrm{ml}$ ) in the 200 culture media. At $72 \mathrm{~h}$ after infection, a transgene was expressed in $>90 \%$ neurons. The cultures were stained with propidium iodide (PI, Sigma) $3 \mathrm{~d}$ (DIV13) or with TUNEL (Millipore) $5 \mathrm{~d}$ (DIV15) after virus particle infections. In some experiments, $5 \mu \mathrm{M}$ Tatp53DM or Tat-s-p53DM, or $50 \mu \mathrm{M}$ BIP-V5 (Millipore), or $10 \mu \mathrm{M}$ pifithrin- $\alpha$ (Sigma) was applied $2 \mathrm{~d}$ after virus infections. Tat-p53DM (Tat-RVCACPGRDRRT) or Tat-s-p53DM (Tat-CCPGECVRTRRR) peptides with $99 \%$ purity were synthesized by AnaSpec. The peptides were numbered and the experimenters were unaware of which one was used in all experiments.

Cloning and generation of $r A A V 1 / 2$ virus particles. cDNA encoding $\mathrm{p} 53$ in $p$ LCRcala (Eddgene, plasmid 12136) or $\mathrm{p}^{2} \mathrm{~A}^{23}$ in $p$ Bluescript II SK (Addgene, plasmid 12167) was used as the template for PCR amplification. The PCR products were digested using SalI and HindIII. The resulting fragment was ligated to a SalI-digested rAVE-GFP vector (GenDetect) to generate rAVE-p53-GFP, or rAVE-p53A ${ }^{23}$-GFP under the control of a CAG promoter and was terminated using the polyadenylation signal in the $3^{\prime}$ long terminal repeat. Downstream of GFP was a woodchuck hepatitis virus regulatory element that enhances the transgene expression. The rAVE-CAG-p53-GFP or rAVE-CAG-p53A ${ }^{23}$-GFP was cotransfected with the AAV helper $1 / 2$ into HEK-293 cells to generate high titers $\left(9 \times 10^{12}\right.$ genomic particles $\left./ \mathrm{ml}\right)$ of $\mathrm{rAAV} 1 / 2$ infectious particles. Cloning and generation of lenti virus ( $p$ Lenti) particles for the expression of $w D A P K 1, c D A P K 1$, or $\mathrm{CDAPK} 1^{\mathrm{DD} \Delta}$ were described previously (Tu et al., 2010).

Real-time PCR. RNA was isolated using TRIzol (Invitrogen) from the cultured neurons $72 \mathrm{~h}$ after transfection of the respective genes (indicated in the figure legends) and reverse transcribed using MMLV reverse transcriptase (Invitrogen) and random primers. PCR was performed in triplicate using SYBR Green (SA-Biosciences) and a 7900HT Fast RealTime PCR machine (Applied Biosystems). The following primers ( $5^{\prime}$ to $3^{\prime}$ ) were used: Bax forward, TGAAGACAGGGGCCTTTTTG and Bax reverse, AATTCGCCGGAGACACTCG; Puma forward, AGCAGCACTTAGAGTCGCC and Puma reverse, CCTGGGTAAGGGGAGGAGT; and $p 53$ forward, CTCTCCCCCGCAAAAGAAAAA and $p 53$ reverse, CGGAACATCTCGAAGCGTTTA. The results were computed using a standard curve made with cDNA pooled from all samples.

Oxygen and glucose deprivation (OGD). The cultured neurons were transferred to an anaerobic chamber containing a $5 \% \mathrm{CO}_{2}, 10 \% \mathrm{H}_{2}$, and $85 \% \mathrm{~N}_{2}$ atmosphere. The cells were then washed $3 \times$ with $500 \mu \mathrm{l}$ of deoxygenated glucose-free bicarbonate solution and maintained anoxic at $37^{\circ} \mathrm{C}$ for $60 \mathrm{~min}$ and $90 \mathrm{~min}$, respectively. OGD was terminated by washing the cultures with oxygenated glucose-containing $(20 \mathrm{~mm})$ bicarbonate solution. The cultures were maintained for $72 \mathrm{~h}$ at $37^{\circ} \mathrm{C}$ in a humidified $5 \% \mathrm{CO}_{2} / 10 \% \mathrm{H}_{2} / 85 \% \mathrm{O}_{2}$ atmosphere. The cultures were used for Western blotting, real-time PCR, and PI and TUNEL staining. 
A

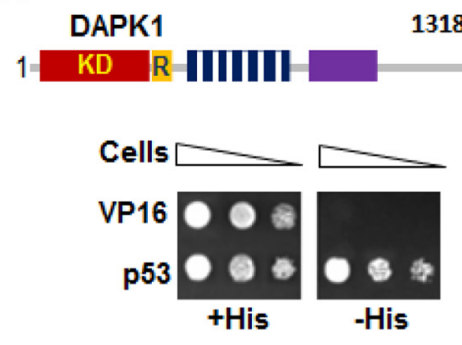

B

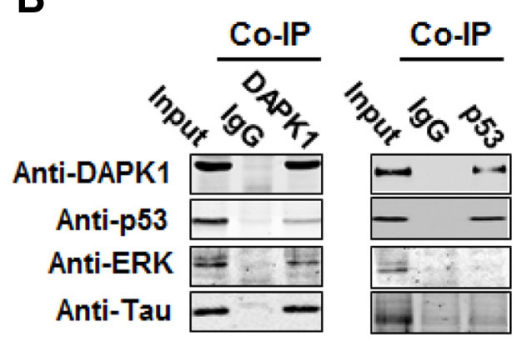

C

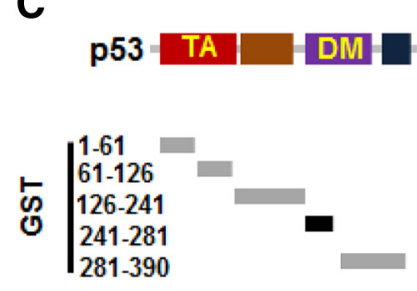

D

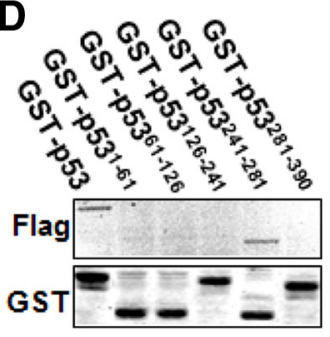

F

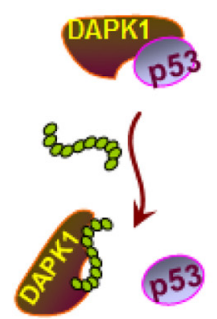

G

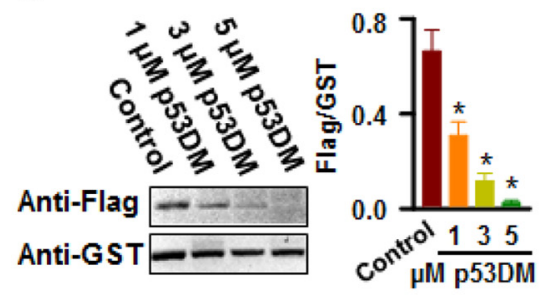

E

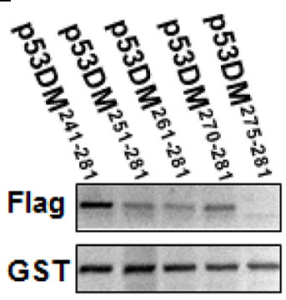

H

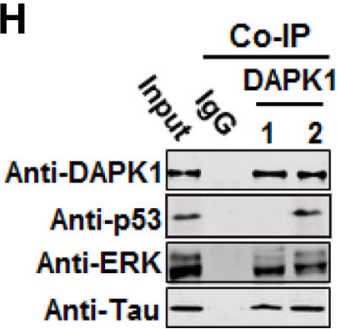

Figure 1. Direct binding of DAPK1DD to p53DM. A, Yeast two-hybrid screen of $\mathrm{p} 53$ as an interactive partner of DAPK1DD was found in a mouse whole-brain cDNA library. Strains were spotted at decreasing cell density on plates that allow for growth without (+ His) or only with (-His + 3-AT). B, Coimmunoprecipitation of $500 \mu \mathrm{g}$ proteins from the adult mouse cerebral cortex with nonspecific lgG (IgG), anti-DAPK1 (DAPK1), or anti-p53 (p53), as indicated. The precipitates were probed with antibodies against DAPK1, p53, ERK, or Tau protein, as indicated. Input: $30 \mu \mathrm{g}$ of protein of the extracts without IP was loaded. C, The constructs showing GST-p53 and GST-p53 mutantsfrom a mouse full-length $p 53^{1-390}$. D, The affinity binding assay showing that Flag-tagged DAPK1DD bindsto GST-p53DM ${ }^{241-281}$.E, The affinity binding assay showing a minimal binding region of DAPK1DD in a sequence consisting of amino acids $270-281$ of p53DM. $\boldsymbol{F}$, An illustration showing that the p53DM peptide inhibits the DAPK1-p53 association. G, Thep53DM peptide at $5 \mu$ m incubated in affinity binding assay buffer and completely eliminates a direct binding of Flag-tagged DAPK1DD with GST-p53. Data are mean \pm SEM (ANOVA, $F_{(3,11)}=5.26,{ }^{*} p<$ $0.01, n=5 /$ group). $\boldsymbol{H}$, Application of p53DM disrupts DAPK1 association with p53, but not with ERK and Tau proteins. Coimmunoprecipitation of $500 \mu \mathrm{g}$ proteins from the adult mouse cerebral cortex was performed with nonspecific $\operatorname{lgG}(\mathrm{lgG})$ or anti-DAPK1 (DAPK1). The precipitates were then incubated with $5 \mu \mathrm{m}$ p53DM (lane 1) or a scrambled control (lane 2). The precipitates were probed with antibodies against DAPK1, p53, ERK, or Tau proteins, as indicated. $\boldsymbol{B}, \boldsymbol{E}, \boldsymbol{H}$, Similar results were observed in each of the five experiments.

The numbers of PI- and TUNEL- labeled cells were expressed as a percentage of total numbers of DAPI-labeled cells per condition.

Statistical analysis. All variance values in the text and figure legends are presented as mean \pm SEM. Parametric tests, including $t$ test and ANOVA, were used where assumptions of normality and equal variance $(F$ test $)$ were met. In some analyses, Student-Newman-Keuls post hoc tests after ANOVA were performed, as described in the respective figure legends.

Animal care. Male adult (4 months old of age) C57BL/6J mice were used in this study. Care and experiments with mice were in accordance with institutional guidelines of the Animal Care and Use Committee (Huazhong University of Science and Technology, Wuhan, China).

\section{Results}

DAPK1DD binds to p53DM directly

To identify a specific cell death signaling molecule downstream of DAPK1, we performed yeast two-hybrid analysis using DAPK1DD as bait. The screen of a mouse whole-brain cDNA library detected p53, extracellular signal-regulated kinase (ERK) and Tau as interacting substrates of DAPK1 (Fig. 1A). Among them, p53 is a transcriptional regulator and controls the program of necrotic and apoptotic pathways of cell death (Copani et al., 2001; Green and Kroemer, 2009; Maiuri et al., 2009; Vaseva et al., 2012). To validate this interaction in brain cells in vivo, we precipitated the endogenous DAPK1 complex in the cellular extracts of the adult mouse cerebral cortex using antibodies against DAPK1 and p53. We probed the precipitates with antibodies against p53, ERK, or Tau and showed the existence of endogenous p53, ERK, and Tau proteins in the DAPK1 complex (Fig. 1B). These findings demonstrated that DAPK1 was physically associated with p53, ERK, and Tau proteins.

To map a binding region of DAPK1DD with $\mathrm{p} 53$, we generated a glutathione S-transferase (GST) protein fused to p53 (GST-p53) and GST-p53 deletion mutants, including GST-p53 $3^{1-61}$, GST-p53 ${ }^{61-126}$, GST-p53 ${ }^{126-241}$, GST-p53 ${ }^{241-281}$, and GST-p53 ${ }^{281-390}$ (Fig. 1C). We performed an affinity binding assay by incubating the GST fusion proteins with a Flag-tagged DAPK1DD in vitro. We found that DAPK1DD bound to a p53 DNA binding motif consisting of amino acid 241-281 (p53DM ${ }^{241-281}$; Fig. 1D).

We subsequently screened a series of $\mathrm{p} 53 \mathrm{DM}^{241-281}$ deletions and identified a peptide consisting of amino acid 270-281 $\left({ }^{270}{ }^{R V C A C P G R D R R T}{ }^{281}, \mathrm{p} 53 \mathrm{DM}\right)$ in the $\mathrm{p}^{2} 3 \mathrm{DM}^{241-281}$ fragment as a minimal binding region of DAPK1DD (Fig. 1E). The direct binding of DAPK1DD to p53DM was verified using peptide blocking experiments (Fig. $1 F, G$ ). In these experiments, a 
synthesized p53DM peptide at $5 \mu \mathrm{M}$ completely blocked the binding of Flag-tagged DAPK1DD to GST-p53DM in vitro but did not affect DAPK1 association with ERK or Tau protein (Fig. 1H). These data demonstrated that DAPK1 interacted with p53 in brain cells in vivo via a direct binding of DAPK1 DD to p53DM.

\section{DAPK1 functionally interacts with p53}

To determine whether DAPK1 functionally interacts with $\mathrm{p} 53$, we used a p53 transcriptional response element reporter system to analyze p53 targeting genes in HEK293 cells. We coexpressed constitutively active DAPK1 (cDAPK1) lacking an autoinhibitory domain of DAPK1 (amino acids 266-312), or wildtype DAPK1 (wDAPK1) with the reporter in HEK293 cells. We found that cDAPK1, as an active form of DAPK1, induced a fivefold increase of the reporter activity (Fig. 2A). This increase was abolished by knocking down of endogenous p53 using a small interference RNA (p53siRNA) that specifically targets to the $p 53$ gene. A scrambled p53siRNA (s-siRNA) was used as a negative control. Deletion of cDAPK1DD $\left(\mathrm{cDAPK}^{\mathrm{DD}}{ }^{\mathrm{D}}\right)$, which eliminates cDAPK1-p53DM binding, was ineffective to alter the p53 reporter genes. Because 553 protein was not changed when cDAPK1 was expressed (Fig. 2B), cDAPK1 activated the p53 reporter via a direct binding of DAPK1DD to p53DM.

\section{DAPK1 phosphorylates $\mathrm{p} 53$ at serine- $23\left(p \mathrm{~S}^{23}\right)$}

DAPK1 is considered a kinase of human p53 at serine-20 $\left(p S^{20}\right)$ (Craig et al., 2007), a residue corresponding to mouse p53 at serine-23 ( $\mathrm{p}^{2} 3 \mathrm{~S}^{23},{ }^{19} \mathrm{QETFSGL}{ }^{25}$ ). We thus tested whether activated DAPK1 phosphorylates $p 53 S^{23}\left(p S^{23}\right)$ in the cortical neurons from mice. We reconstituted the $\mathrm{p} 53^{-1-}$ cortical neurons with the expression of cDAPK 1 and a wild-type $\mathrm{p} 53$ or its mutant $\mathrm{p} 53 \mathrm{~A}^{23}$. We also developed an antibody against $p \mathrm{~S}^{23}$. Our results demonstrated that anti- $p S^{23}$ specifically recognized $p S^{23}$, but not mutant $\mathrm{p} 53 \mathrm{~A}^{23}$ (Fig. 2 C). The activated CDAPK1, but not inactivated wDAPK1, induced $p S^{23}$ (Fig. $2 D$ ). We also expressed cDAPK $1{ }^{\mathrm{DD} \Delta}$ and added a membrane-permeable p53DM peptide (Tat-p53DM) generated by fusing p53DM to the cell-membrane transduction domain of the HIV-1 Tat protein. We found that the expression of cDAPK $1^{\mathrm{DD} \Delta}$ or application of Tat-p53DM effectively blocked the direct binding of DAPK1DD to p53DM and completely eliminated anti- $p S^{23}$ signals in the cytosolic fraction of the proteins, whereas a scrambled Tat-s-p53DM did not (Fig. $2 D, E)$. In addition to p53, DAPK1 interacted with ERK and Tau proteins. Thus, it is likely that $p S^{23}$ was phosphorylated indirectly via DAPK1-ERK or DAPK1-Tau interactions. To address this possibility, we expressed small interference RNA (siRNA) that specifically silences the ERK (E-siRNA) or Tau (T-siRNA) gene in the cultured neurons when cDAPK1 was expressed. s-siRNA was expressed as a control. We found that neither E-siRNA nor T-siRNA altered $p \mathrm{~S}^{23}$ level in the cytoplasmic fraction of the cultured neurons in the presence of cDAPK1 (Fig. 2E). Previous studies indicated that expression of exogenous p53 is sufficient to cause the death of cultured neurons (Slack et al., 1996; Xiang et al., 1996; Jordán et al., 1997). Accordingly, we hypothesized that the expression of exogenous $\mathrm{p} 53$ may induce $p \mathrm{~S}^{23}$ production. To test this hypothesis, we introduced exogenous p53 gene in the $\mathrm{p} 53^{+/+}$ and $\mathrm{p}^{-1-}$ neurons, respectively, and showed that it did not induce $p \mathrm{~S}^{23}$ expression (Fig. $2 F$ ). Thus, cDAPK1 catalyzes $\mathrm{p} 53$ into the $p \mathrm{~S}^{23}$ via the direct binding of cDAPK1DD to p53DM.

\section{$p \mathrm{~S}^{23}$ nuclear translocation induces proapoptotic gene expression}

p53 is a transcriptional regulator and controls proapoptotic gene expression (Brady et al., 2011; Vaseva et al., 2012). We next determined whether $p S^{23}$ represents a functional version of $\mathrm{p} 53$. First, we examined its subcellular distributions. We purified a nuclear fraction from the cortical cells. Western bloting revealed that the $p \mathrm{~S}^{23}, \mathrm{p} 53$, and a nuclear matrix protein $\mathrm{p} 84$ were enriched in the nucleus of the $\mathrm{p} 53^{+/+}$neurons expressing cDAPK1 (Fig. $2 G$ ). In contrast to $p S^{23}$, DAPK1 protein was largely restricted to the cytoplasm (Fig. 2D). Thus, activated DAPK1 catalyzed $\mathrm{p} 53$ into $p \mathrm{~S}^{23}$ outside the nucleus. The presence of $p S^{23}$ in the nucleus reflects $p S^{23}$ nuclear translocation. We also stained the cultured neurons with antibodies against the $p \mathrm{~S}^{23}$ and $\mathrm{p} 53$ (Fig. $2 H$ ) or mitochondrial protein (COX-IV, Fig. 2I). Our results verified that the $p S^{23}$ was located in both the mitochondria and the nucleus in the cultured cortical neurons when cDAPK1 was expressed (Fig. $2 \mathrm{H}, \mathrm{I}$ ). Of note, $\mathrm{p} 53$ protein was detectable in the nucleus in some cultured cortical neurons under the basal condition, although it seemed to be absent in the nucleus in some cultured neurons (Fig. $2 \mathrm{H}$ ). This result is consistent with the results in Figure 2G, showing the presence of p53 protein in the nucleus of a pool of the cultured neurons.

Then, we determined the transcriptional activity of $p S^{23}$ in cortical neurons through analysis of $\mathrm{p} 53$ proapoptotic genes. Our data revealed that Bax and Puma genes (Fig. $3 A-E$ ), but not $p 53 \mathrm{mRNA}$ (Fig. $3 F$ ), were expressed when cDAPK1, but not wDAPK1, was reconstituted in the $\mathrm{p} 3^{+/+}$neurons. Deletion of the $p 53$ gene ( $\mathrm{p} 53^{-1-}$ neurons) or reconstitution of $\mathrm{p} 53 \mathrm{~A}^{23}$ in the $\mathrm{p} 53^{-/-}$neurons blocked the effects of cDAPK1. We found that application of pifithrin- $\alpha$, but not with the vehicle control, completely suppressed the cDAPK1-induced expression of Bax and Puma genes (Fig. 3C,E), but not $p S^{23}$ (Fig. $3 G$ ). Thus, cDAPK1 activated the p53 proapoptotic genes via activation of $p S^{23}$ transcription. We also treated the cortical cultures with a DNA-damaging agent (camptothecin [CPT]). Consistent with previous studies (Uo et al., 2007; Brochier et al., 2013), we found that CPT at $10 \mu \mathrm{m}$ induced the expression of Bax genes (Fig. 3H). However, when a mutant $\mathrm{p} 53 \mathrm{~A}^{23}$ was introduced into the $\mathrm{p} 53^{-1-}$ neurons, it did not compromise the CPT effects, showing that $\mathrm{CPT}$ induced the expression of $\mathrm{p} 53$ proapoptotic genes via the $p S^{23}$-independent mechanism.

\section{$p \mathrm{~S}^{23}$ induces apoptosis via Bax expression}

Bax controls the programs of apoptosis through interaction with Bcl2 family proteins at the outer mitochondrial membrane, resulting in Permeability Transition Pore (PTP) opening (Morris et al., 2001; Steckley et al., 2007; Meulmeester and Jochemsen, 2008). Consistent with this notion, we showed that cDAPK1 activated PTP (Fig. 4A). Application of Tat-p53DM that directly intercepts DAPK1DD-p53DM binding completely inhibited the effects of cDAPK1 (Fig. 4B), Deletion of the $p 53$ gene $\left(\mathrm{p}_{53}{ }^{-1-}\right.$ ) produced the same degree of inhibition as $\mathrm{p} 53 \mathrm{DM}$. This inhibition was completely reversed by the introduction of wild-type $p 53$ gene, but not its mutant $\mathrm{p} 53 \mathrm{~A}^{23}$, into the $\mathrm{p} 53^{-1-}$ neurons, but this was partially affected by application of Bax inhibitor or deletion of Bax gene (Fig. 4C). Thus, the cDAPK1-induced activation of PTP was mediated by $p S^{23}$ through the direct binding of cDAPK1DD to p53DM, but was partially dependent on Bax expression. The PTP opening was associated with cytochrome-c (Cyto-c) release (Fig. 4D), Caspase-3 (Casp3) cleavage (Fig. $4 E, F$ ), and TUNEL labeling (Fig. 4G,H). Expression of exogenous $p 53$ in the $\mathrm{p} 3^{-1-}$ neurons alone in the absence of cDAPK1 caused no neuronal apoptosis (Fig. 4H). This observation is, 

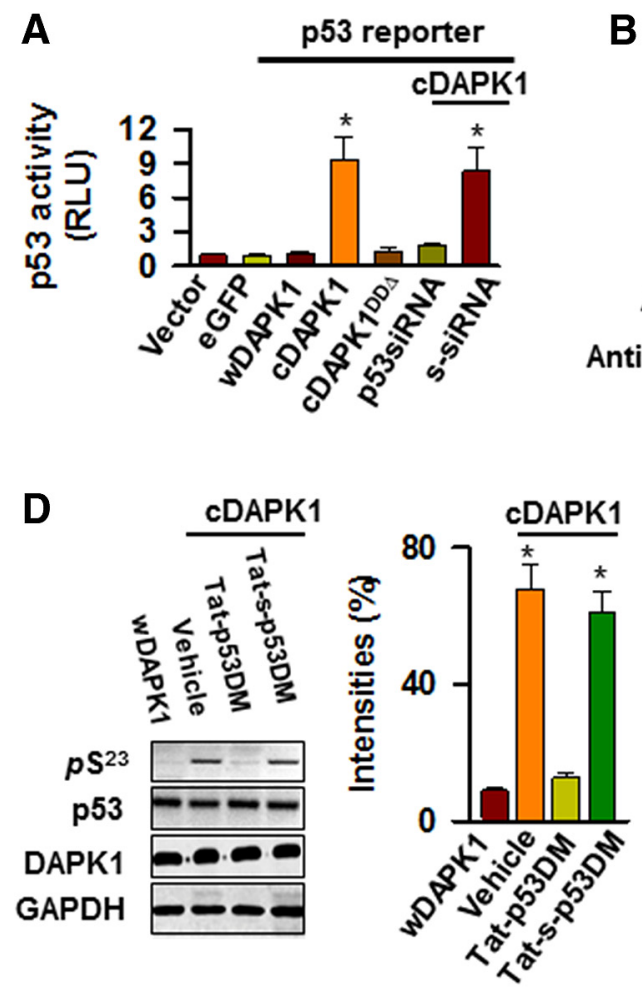

G
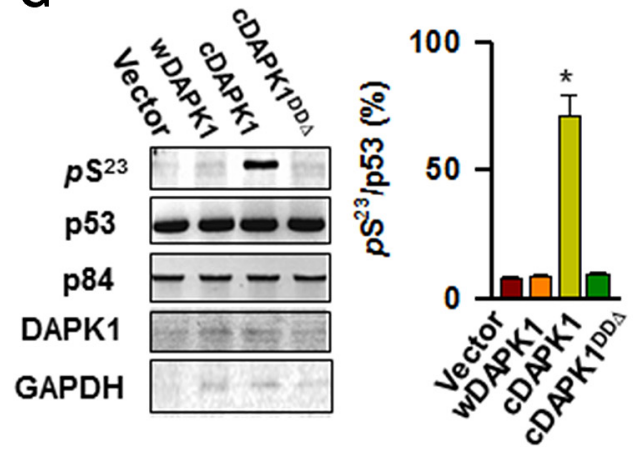
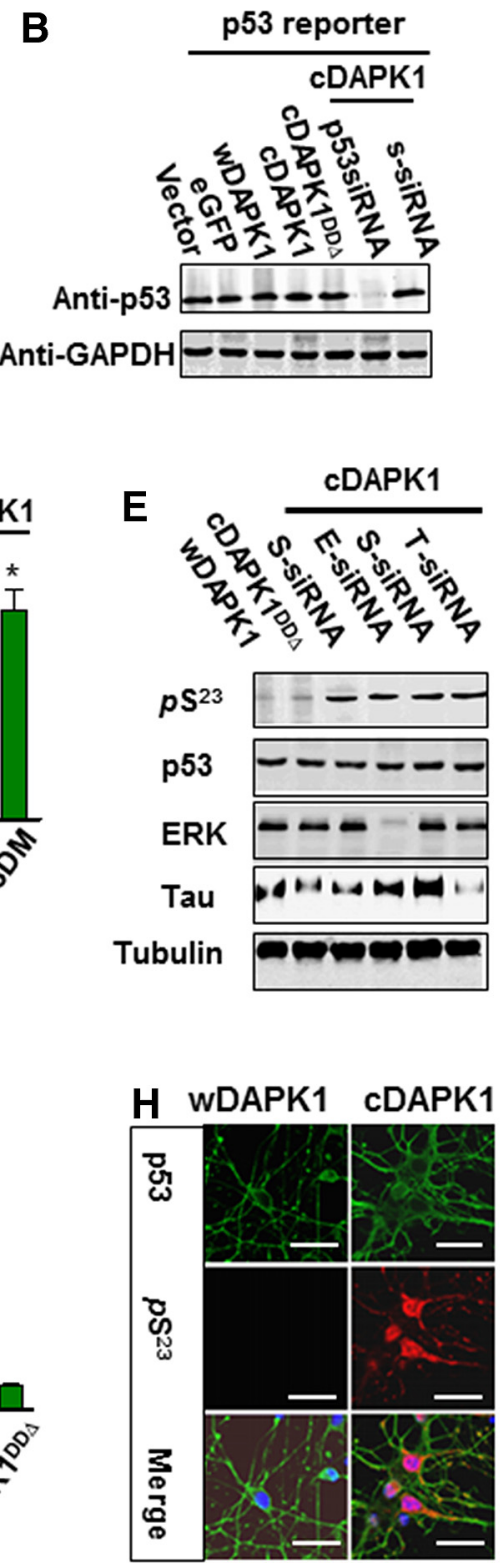
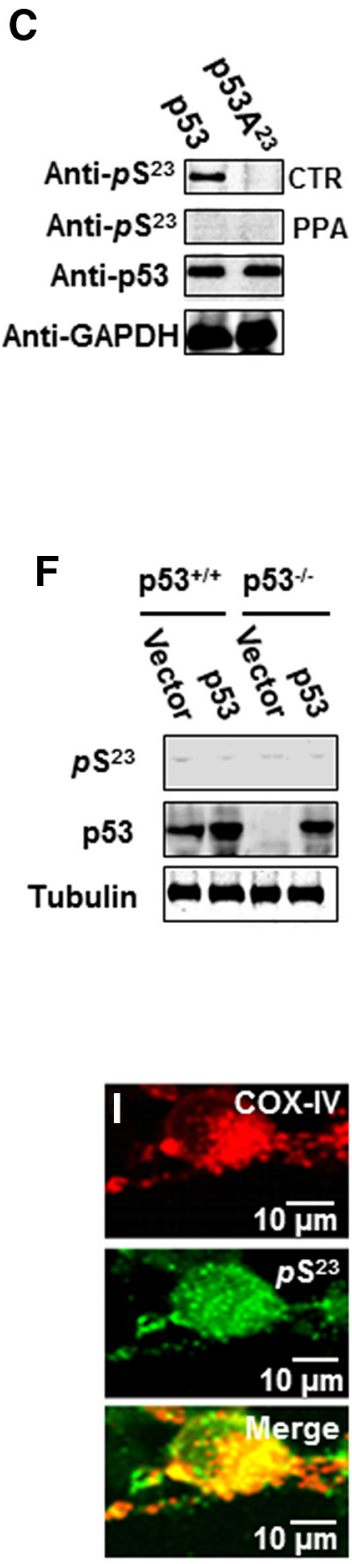

Figure 2. DAPK1 induces $p S^{23}$ accumulation and nuclear translocation. $A, C D A P K 1$ activates $p 53$ reporter genes via a direct binding of CDAPK1DD to $p 53 D M$ in HEK293 cells. Data are mean \pm SEM; $n=5$. ${ }^{*} p<0.01$ (compared with the vector). $\boldsymbol{B}$, The 533 protein unchanged in the presence of CDAPK1. HEK293 cells were transfected with $2 \mu \mathrm{g}$ plasmids, as indicated. At $72 \mathrm{~h}$ after transfection, cell lysates ( $30 \mu \mathrm{g}$ proteins) were prepared and probed with antibodies against 553 or GAPDH, as indicated. Similar results were observed in each of the four experiments. $C$, The cellular extracts from $\mathrm{p} 53^{-1-}$ cells coexpressing CDAPK1 with $\mathrm{p} 53$ or $\mathrm{p} 53 \mathrm{~A}^{23}$ are blotted with anti- $\mathrm{pS}{ }^{23}$ or anti-p53 after treatment with control buffer (CTR) or 100 units of alkaline phosphatase (PPA). Similar results were observed in each of the five experiments. D, CDAPK1DD-p53DM binding induces $p S^{23}$ accumulation. CDAPK1 in the presence of $5 \mu \mathrm{m}$ of a membrane-permeable p53DM (Tat-p53DM) peptide or scrambled control (Tat-s-p53DM), or vehicle, or CDAPK1 ${ }^{\mathrm{DD} \Delta}$ alone was expressed in DAPK1 ${ }^{-1-}$ cortical neurons. At $72 \mathrm{~h}$ after the expression, the cellular proteins were prepared and blotted with antibodies against $p S^{23}, p 53$, DAPK1, or GAPDH, as indicated. The $p S^{23}$ band intensities are expressed as the ratio of the respective $p 53$ protein. Data are mean $\pm S E M ; n=5 .{ }^{*} p<0.01 . E$, Inhibition of ERK or Tau does not affect DAPK1-p53 interaction. Cultured cortical neurons (DIV10) were transfected with CDNA encoding wDAPK1, CDAPK1 ${ }^{\text {DD } \Delta}$, or CDAPK1 with a scrambled control small interference RNA (s-siRNA), siRNA that specifically targets to ERK (E-siRNA) or Tau (T-siRNA) using rAAV1/2 viral vector. At $72 \mathrm{~h}$ after transfection, cell lysates were prepared and blotted with antibodies, as indicated. Similar results were observed in each of the four experiments. $\boldsymbol{F}$, The expression of exogenous $p 53$ does not cause $p 5^{23}$ accumulation. Cultured cortical p53 ${ }^{+/+}$and $p 53^{-1-}$ neurons (DIV10) were transfected with CDNA encoding p 53 using a rAAV1/2 viral vector. At $72 \mathrm{~h}$ after transfection, cell lysates were prepared and blotted with antibodies against $p 5^{23}$, p53, or tubulin, as indicated. Similar results were observed in each of the four experiments. $G$, The $p S^{23}$ undergoes nuclear translocation. The nuclear proteins were purified from p53 ${ }^{+/+}$cortical neurons expressing an empty vector, wDAPK1, CDAPK1, or CDAPK1 ${ }^{\mathrm{DD} \Delta}$ using individual rAAV1/2 viral vector. At $72 \mathrm{~h}$ after expression, cell lysates were prepared and probed with antibodies, as indicated. $p S^{23}$ band intensity is expressed as the ratio of the respective $p 53$ protein. Data are mean $\pm \mathrm{SEM} ; n=4 .{ }^{*} p<0.01$. $\boldsymbol{H}$, The $p S^{23}$ is expressed in the nucleus. The cultured cortical neurons (DIV10) were transfected with wDAPK1 or CDAPK1 using the individual rAAV1/2 virus vector. At $72 \mathrm{~h}$ after the transfection, the cultures were stained with antibodies against p53 (green), or $p \mathrm{~S}^{23}$ (red) and DAPI (blue), as indicated. Similar results were seen in each of the five experiments. Scale bar, $50 \mu \mathrm{m} . I, p 5^{23}$ is colocalized with mitochondrial protein, COX-IV. The cultured cortical neurons (DIV10) were transfected with CDAPK1 using the rAAV1/2 viral vector. At $72 \mathrm{~h}$ after the transfection, the cultures were stained with antibodies against $p \mathrm{~S}^{23}$ and $\mathrm{COX}$-IV, respectively.

however, inconsistent with the previous reports that the expression of an exogenous $p 53$ gene is sufficient for the induction of neuronal apoptosis (Slack et al., 1996; Xiang et al., 1996; Jordán et al., 1997). This inconsistency could be due to the different $p 53$ genes used in the different studies; the mouse $p 53$ gene was used in the present study, whereas the human $p 53$ gene was used in the previous reports. Thus, our results demonstrated that $p S^{23}$ was an essential substrate of CDAPK1 and activated apoptosis by expres- 
A

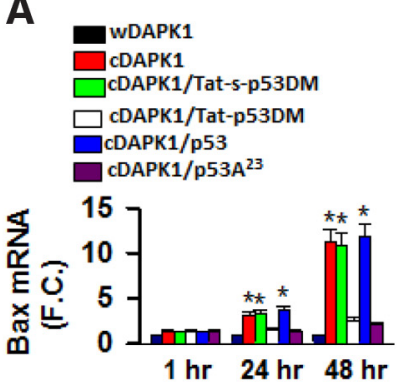

D

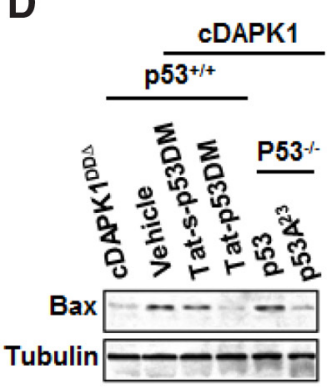

F

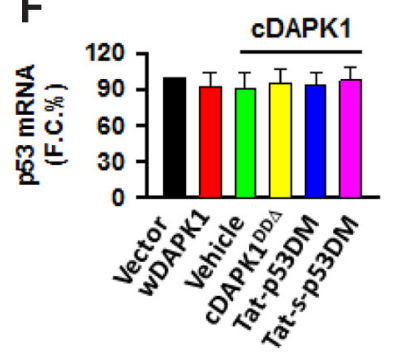

B
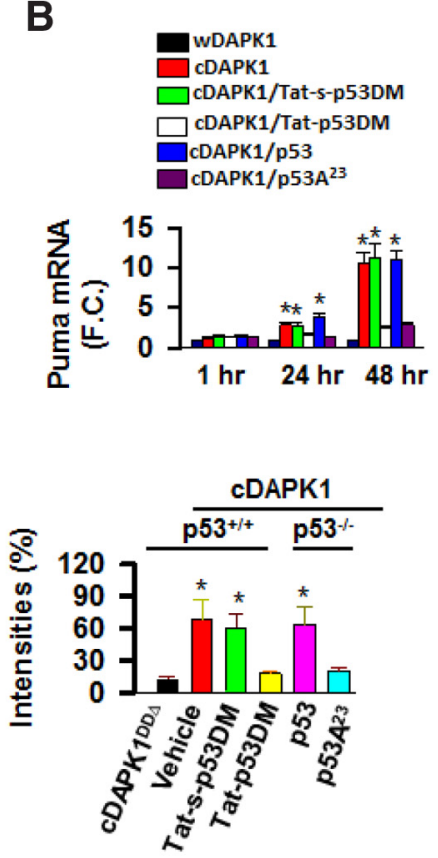

G

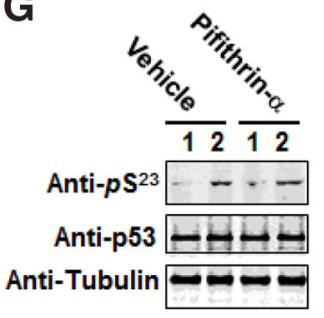

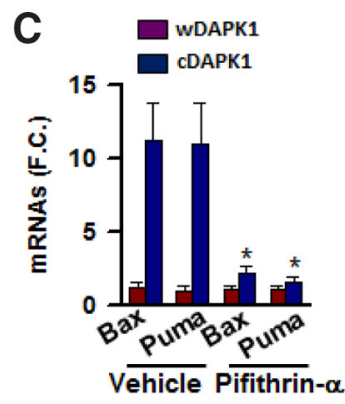

E

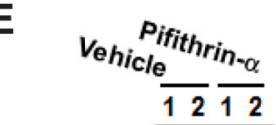

Anti-Bax -

Anti-Tubulin $\rightarrow \pi \pi$

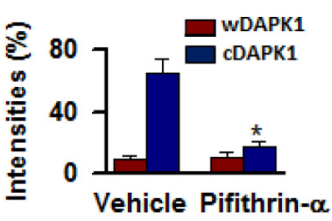

Figure 3. $p S^{23}$ induces the expression of proapoptotic genes. $\boldsymbol{A}, \boldsymbol{B}, \mathrm{qPCR}$ shows $B a x(\boldsymbol{A})$ and Puma mRNAs $(\boldsymbol{B})$ levels in the cultured p53 ${ }^{+/+}$cortical neurons 1,24, or $48 \mathrm{~h}$ after wDAPK1, or $\mathrm{CDAPK1}$ expression in the absence or presence of Tat-p53DM, or Tat-s-p53DM. In the cultured p53 ${ }^{-1-}$ neurons, CDAPK1 was coexpressed with p53 or p53A ${ }^{23}$, as indicated. Data are mean \pm SEM; $n=4$ assays. ${ }^{*} p<0.01$. C, Application of pifithrin- $\alpha$ blocks $p S^{23}$-induced Bax and Puma expression. Cultured $p 53^{+/+}$neurons (DIV10) were transfected with wDAPK1 or cDAPK1 in the presence of $0.5 \%$ DMSO (vehicle) or $10 \mu \mathrm{m}$ pifithrin- $\alpha$. At $72 \mathrm{~h}$ after expression, a total cellular RNA was isolated and analyzed with qPCR. Data are mean \pm SEM; $n=4$ assays. ${ }^{*} p<0.01$. $D, p S^{23}$ induces Bax expression. The cDAPK1 in the presence of vehicle, Tat-s-p53DM, or Tat-p53DM, or CDAPK1 ${ }^{\text {DD } \Delta}$ alone was expressed in p53 ${ }^{+/+}$cortical neurons (DIV10) or CDAPK1 alone was coexpressed with p53 or $\mathrm{p} 53 \mathrm{~A}^{23}$ in the $\mathrm{p} 53^{-1-}$ cortical neurons (DIV10). At $72 \mathrm{~h}$ after expression, cellular proteins were prepared and blotted with anti-Bax. The band intensities are normalized to the respective anti-tubulin. Data are mean \pm SEM; $n=5 /$ group. ANOVA: $F_{(6,28)}=5.38,{ }^{*} p<0.01$. E, Application of pifithrin- $\alpha$ blocks the $p S^{23}$-induced Bax and Puma expression. The cultured $p 53{ }^{+} /+$neurons (DIV10) were transfected with wDAPK1 or CDAPK1 in the presence of $0.5 \%$ DMSO (vehicle) or $10 \mu \mathrm{m}$ pifithrin- $\alpha$. At $72 \mathrm{~h}$ after expression, cellular proteins were prepared and blotted with anti-Bax. Data are mean $\pm \mathrm{SEM} ; n=4$ assays. ${ }^{*} p<0.01$. $\boldsymbol{F}$, CDAPK1 expression has no effect on $p 53$ mRNA expression. qPCR shows the levels of $p 53$ mRNA in DAPK1 ${ }^{-/-}$cortical neurons $72 \mathrm{~h}$ after the expression of wDAPK1, CDAPK1, CDAPK1 ${ }^{\text {DD } \Delta}$, or CDAPK1 in the presence of Tat-p53DM or Tat-s-p53DM, as indicated. Data are mean \pm SEM; $n=4$ assays. ${ }^{*} p<0.01$. $\mathbf{G}$, Inhibition of $p 53$ transcription does not affect the $p S^{23}$ accumulation. Cultured cortical neurons (DIV10) were transfected with wDAPK1 (lane 1) or CDAPK1 (lane 2) in the presence of vehicle or $10 \mu m$ pifithrin- $\alpha$, as indicated. At $72 \mathrm{~h}$ after transfection, cell lysates were prepared and blotted with antibodies against $p \mathrm{~S}^{23}$ or $\mathrm{p53}$, as indicated. Similar results were observed in each of the four experiments. $\boldsymbol{H}$, Application of camptothecin induces Bax expression via the $p S^{23}$-independent mechanism. The cultured cortical p53 $3^{+/+}$and p53 $3^{-1-}$ neurons (DIV10) were transfected with p53, or p53A ${ }^{23}$ in the presence of $10 \mu \mathrm{m}$ CPT or vehicle. At $72 \mathrm{~h}$ later, total RNA was extracted for qPCR analysis. Data are mean $\pm \mathrm{SEM} ; n=5$ per treatment. ${ }^{*} p<0.01$.

sion of the p53 proapoptotic genes. As mentioned above, application of pifithrin- $\alpha$ that blocks $p 53$ transcription or of a Bax Inhibitory Peptide (BIP-V5) that directly inhibits Bax, or deletion of Bax gene $\left(\mathrm{Bax}^{-/-}\right)$, produced only partial inhibition of PTP (Fig. $4 C$ ), although each of these treatments was able to block Cyto- $c$ release (Fig. $4 D$ ), Casp3 activation (Fig. $4 E, F$ ), and neuronal apoptosis (Fig. $4 G, H$ ). Thus, PTP activation by $p S^{23}$ involved both Bax-dependent and -independent mechanisms.

$p \mathrm{~S}^{23}$ interacts with $\mathrm{CypD}$

p53 interacts with CypD in the mitochondrial matrix and activates PTP, leading to cell necrosis (Vaseva et al., 2012). Accordingly, we focused our studies on an interaction of $p S^{23}$ with CypD. We coexpressed cDAPK1 in the $\mathrm{p} 53^{-/-}$cortical cells with wild-type $\mathrm{p} 53$ or its mutant $\mathrm{p} 53 \mathrm{~A}^{23}$. Mitochondrial fractions were then purified from these cortical cultures. To verify the purification of individual mitochondrial fractions, we used antiVDAC (voltage-dependent anion channel; Fig. 5A) for mitochondrial (Mit) membrane and anti-uMTCK (ubiquitous mitochondrial creatine kinase, Fig. $5 B$ ) for the outer membrane $(\mathrm{OM})$, and anti-CypD for the inner membrane (IM; Fig. $5 C$ ) loading controls. We found that $p \mathrm{~S}^{23}$ was enriched in the mitochondrial IM when CDAPK1 and p53 were both expressed (Fig. $5 A-D)$. Incubation of the cultured neurons with $5 \mu \mathrm{M}$ Tatp53DM, but not Tat-s-p53DM blocked the $p S^{23}$ expression in the mitochondrial IM (Fig. 5C). Anti-CypD antibody precipitated endogenous $p \mathrm{~S}^{23}$ in the IM fraction from the $\mathrm{p} 53^{+/+}$, but not p53 $3^{-1-}$ neurons when cDAPK1 was expressed (Fig. $5 E$ ). We subsequently used antibodies against p53 (Fig. $5 F$ ) or $\mathrm{pS}^{23}$ (Fig. $5 G$ ) to precipitate endogenous $\mathrm{CypD}$. Blots of the precipitates re- 

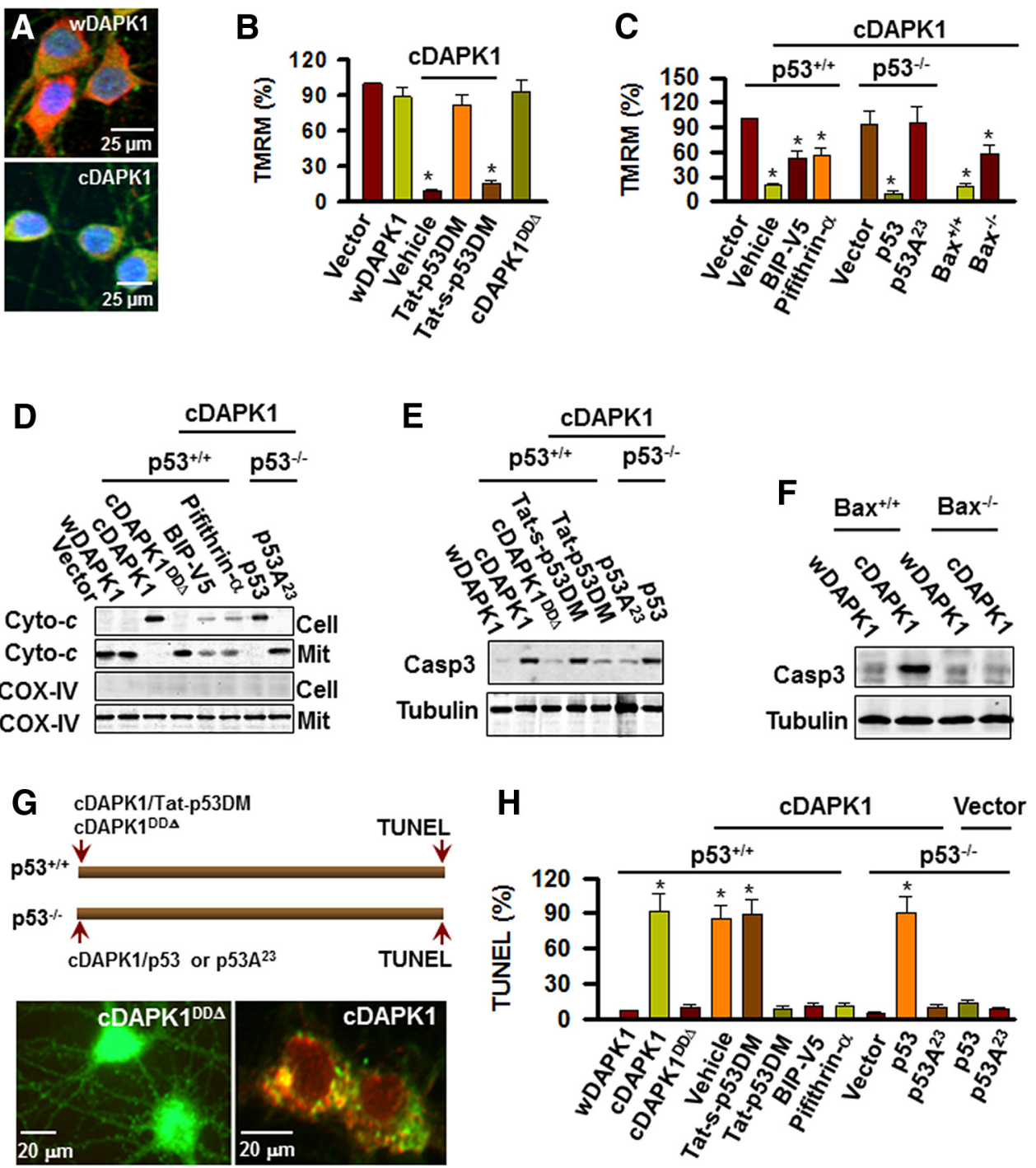

Figure 4. $\quad p S^{23}$ activates Bax-dependent apoptosis. $A$, Representative images showing TMRM fluorescence in DAPK1 ${ }^{-1-}$ cortical neurons with reconstitution of wDAPK1 (red) or CDAPK1 (green). $B, C D A P K 1$ activates mitochondrial PTP via a direct binding of CDAPK1DD to p53DM. An empty vector, wDAPK1, or CDAPK1 in the presence of vehicle, Tat-s-p53DM, or Tat-p53DM, or CDAPK1 ${ }^{\text {DD } \triangle}$ alone was expressed in the cultured DAPK1 ${ }^{-I-}$ neurons (DIV10) using the individual rAAV1/2 viral vector. At $48 \mathrm{~h}$ after expression, the cells were stained with TMRM. Data are normalized to the vector group (defined as 100\%). Data are mean \pm SEM; $n=5 /$ group. ANOVA: $F_{(5,24)}=12.8,{ }^{*} p<0.01$. C, CDAPK1 activates PTP partially via the expression of Bax. CDAPK1 in the presence of BIP-V5 or pifithrin- $\alpha$ was expressed in DAPK $1^{-/-} / \mathrm{p} 53^{+/+}$neurons or coexpressed with $\mathrm{p} 53$ or $\mathrm{p} 53 \mathrm{~A}^{23}$ in $\mathrm{p} 53^{-/-}$neurons or expressed in Bax ${ }^{-/-}$neurons alone, as indicated. Data are mean \pm SEM; $n=5 /$ group. ANOVA: $F_{(6,2)}=11.3,{ }^{*} p<0.01$. D, The DAPK1-p53 interaction induces Cyto-c release. CDAPK1 in the presence of BIP-V5 or pifithrin- $\alpha$ was expressed in the DAPK1 ${ }^{-/-} /$p53 ${ }^{+/+}$ neurons or coexpressed with p53 or p53 ${ }^{23}$ in the $553^{-1-}$ neurons. At $48 \mathrm{~h}$ after the expression, mitochondrial (Mit) and cellular (Cell) proteins were prepared and blotted with anti-Cyto-c and anti-COX-IV antibodies, as indicated. $\boldsymbol{E}$, The DAPK1-p53 interaction activates caspase-3. The cultured cortical $p 53^{+/+}$neurons (DIV10) were transfected with wDAPK1, CDAPK1 ${ }^{\text {DD } \Delta}$, or CDAPK1 in the absence or in the presence of Tat-p53DM or Tat-s-p53DM. At 48 hafter transfection, the cell lysates were prepared and blotted with antibodies against a cleaved caspase-3 (Casp3, activated form) or tubulin, as indicated. Similar results were observed in each of the five experiments. $F$, Deletion of Bax gene blocks Casp3 activation. Cultured cortical Bax ${ }^{+/+}$and Bax ${ }^{-1-}$ neurons (DIV10) were transfected with wDAPK1 or cDAPK1. At $48 \mathrm{~h}$ after the transfection, the cellular proteins were prepared and blotted with anti-Casp3. Similar results were seen in each of the four experiments. G, The DAPK1-p53 interaction induces apoptosis. An illustration (top) showing the experimental arrangements. Representative images (bottom) showing $\mathrm{p}^{+/+}$cortical neurons (DIV10) transfected with cDAPK1 ${ }^{\text {DD }}$-eGFP or CDAPK1-eGFP using individual rAAV1/2 viral vector. At $72 \mathrm{~h}$ after the transfection, the cultures were stained with TUNEL (red), as indicated. $\boldsymbol{H}$, The DAPK1-p53 interaction induces Bax-dependent apoptosis. The cultured cortical p53 ${ }^{+/+}$neurons (DIV10) were transfected with wDAPK1, CDAPK1 ${ }^{\mathrm{DD} \Delta}$, or CDAPK1 in the absence or presence of Tat-p53DM or Tat-s-p53DM, or $10 \mu \mathrm{m}$ pifithrin- $\alpha$, or BIP-V5. In p53 ${ }^{-1-}$ neurons, exogenous p53 or p533 ${ }^{23}$ was transfected alone or cotransfected with CDAPK1. Five days after transfection, the cultures were stained with TUNEL. Data are mean \pm SEM; $n=5 /$ group. ANOVA: $F_{(10,44)}=9.32,{ }^{*} p<0.01$.

vealed that endogenous $\mathrm{CypD}$ was physically associated with both p53 and $\mathrm{pS}^{23}$ proteins in CypD ${ }^{+/+}$neurons (Fig. $5 F, G$ ). This association was not affected by inhibition of p53 transcription through application of pifithrin- $\alpha$ (Fig. $5 H$ ). Furthermore, we found that deletion of $C y p D$ gene produced partial inhibition of PTP activation (Fig. 5I), but it did not affect Cyto-c release and Casp3 activation (Fig. 5J). Thus, these results showed that $p S^{23}$ was physically associated with CypD in the mitochondrial inner membrane compartments. But this association was not required for Cyto-c release and neuronal apoptosis in response to DAPK1 activation.

$p \mathrm{~S}^{23}$ induces cell necrosis via interaction with CypD

We next tested whether the $p \mathrm{~S}^{23}$-CypD association induces neuronal necrosis. We expressed cDAPK1 in the cultured cortical neurons. Three days later, the cultures were stained with PI alone (Fig. $6 A, B$ ) or together with TUNEL (Fig. $6 C$ ). We found that both PI and TUNEL labeling was effectively protected by deletion 

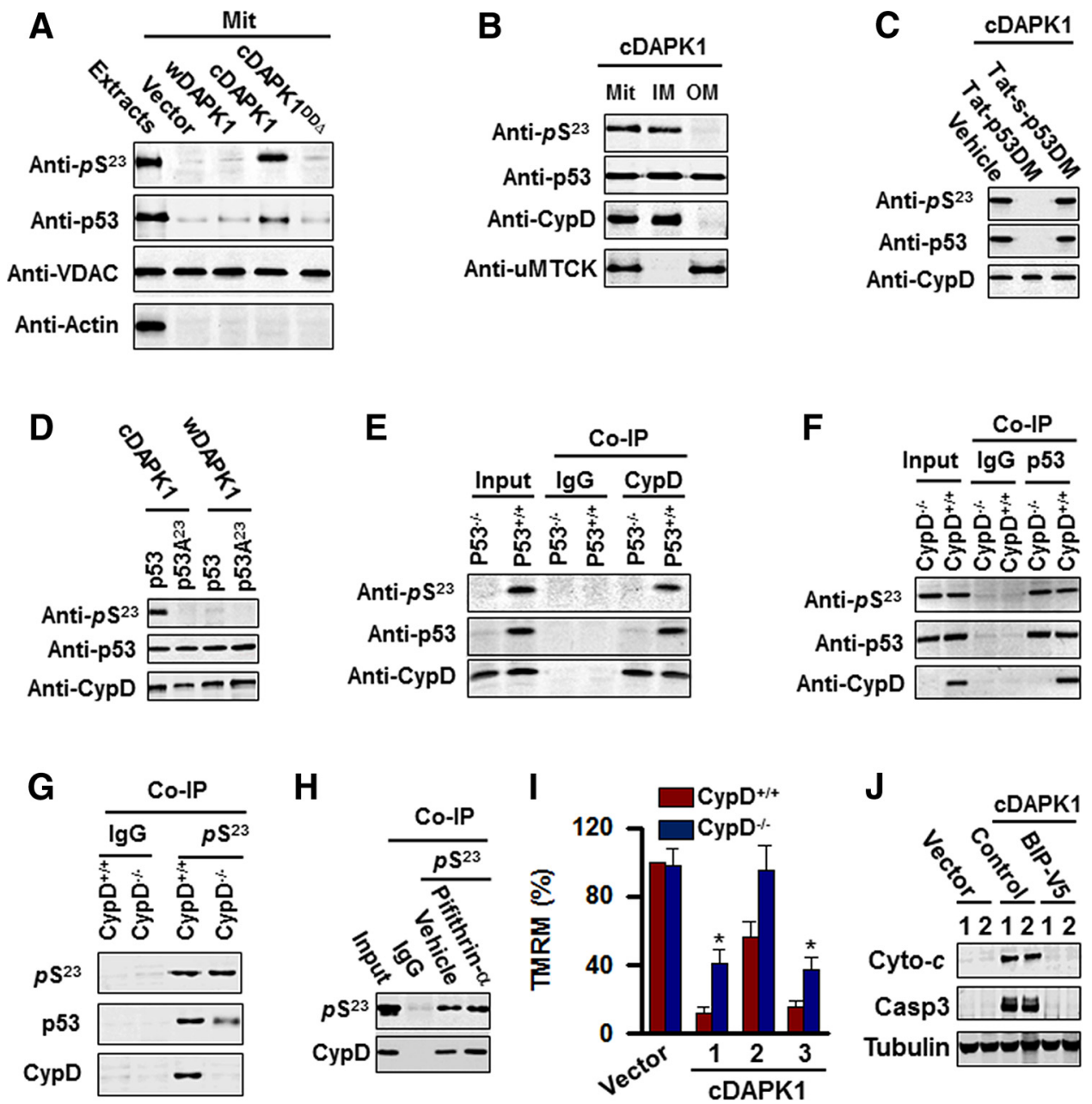

Figure 5. $p S^{23}$ interacts with CypD in the inner mitochondrial membrane. A, CDAPK1 causes $p S^{23}$ accumulation in the mitochondrial fraction. Cultured cortical neurons (DIV10) were expressed with an empty vector, wDAPK1, CDAPK1, or CDAPK1 ${ }^{\mathrm{DD} \Delta}$ using individual rAAV1/2 viral vector. At $72 \mathrm{~h}$ after expression, cellular extracts (Extracts, $30 \mu \mathrm{g}$ proteins) and mitochondrial fractions (Mit) were purified and blotted with antibodies, as indicated. $\boldsymbol{B}$, Western blots of the purified mitochondria (Mit, $30 \mu \mathrm{g}$ proteins), inner membrane (IM), and outer membrane (OM) from the cultured mouse cortical neurons expressing CDAPK1. C. Western blots of the inner membrane proteins ( $30 \mu \mathrm{g}$ proteins) from cultured cortical neurons expressing CDAPK1 in the presence of $5 \mu \mathrm{M}$ Tat-p53DM or Tat-s-p53DM. D, Western blots of inner membrane proteins from cultured $p 53^{-1-}$ cortical neurons coexpressing cDAPK1 or wDAPK1 with p53 or p53A ${ }^{23}$, as indicated. $E-G$, The $p S^{23}$ is associated with CypD. Cultured $\mathrm{p} 53^{-/-} / \mathrm{CypD}^{+/+}(\boldsymbol{E})$ and $\mathrm{p} 53^{+/+} / \mathrm{CypD}^{-/-}(\boldsymbol{F}, \boldsymbol{G})$ cortical neurons were expressed with CDAPK1 using the rAAV1/2-CDAPK1 viral vector. At $72 \mathrm{~h}$ after expression, inner membrane proteins were purified and precipitated with nonspecific $\operatorname{lgG}(\mathrm{lg} G)$ or antibodies against $C y p D(\boldsymbol{E})$, or $p 53(\boldsymbol{F})$, or $p S^{23}(\boldsymbol{G})$, as indicated. The precipitates were blotted with anti-p $S^{23}$, anti-p53, or anti-CypD. $\boldsymbol{H}$, Inhibition of $\mathrm{p} 53$ transcription does not alter $p S^{23}$ accumulation. The cultured cortical neurons were expressed with cDAPK1 in the presence of $10 \mu \mathrm{m}$ pifithrin- $\alpha$ or vehicle $\left(0.5 \%\right.$ DMSO). At $72 \mathrm{~h}$ after expression, the inner membrane proteins were purified and precipitated with nonspecific $\operatorname{lgG}(\mathrm{lgG})$ or anti-p $\mathrm{S}^{23}$. The precipitates were blotted with anti-p $\mathrm{S}^{23}$, or anti-CypD, as indicated. I, CDAPK1 activates PTP partially via interaction with CypD. Cultured CypD ${ }^{+/+}$and CypD ${ }^{-/-}$neurons (DIV10) were expressed with an empty vector or CDAPK1 in the absence (bar 1) or presence of $10 \mu \mathrm{m}$ BIP-V5 (bar 2) or vehicle (bar 3). At $48 \mathrm{~h}$ after expression, the cells were stained with TMRM. Data are normalized to the empty vector group (defined as $100 \%$ ). Data are mean \pm SEM; $n=5 /$ group. ${ }^{*} p<0.01$.J, The $\mathrm{S}^{23}$-CypD interaction does not alter Cyto-c release and Casp3 accumulation. Cultured CypD ${ }^{+/+}$(lane 1) and CypD ${ }^{-1-}$ (lane 2) cortical neurons (DIV10) were transfected with an empty vector or CDAPK1 in the presence of control or $10 \mu \mathrm{M}$ BIP-V5. At $48 \mathrm{~h}$ after transfection, the cell lysates were prepared and blotted with antibodies against Cyto-C, or Casp3 or tubulin, as indicated. $A-J$, Similar results were seen in each of the five experiments.

of $p 53$ gene (p53-l-; Fig. $6 D$ ). Significantly, this protection was completely reversed by reconstitution of a wild-type p53, but not a mutant $p 53 \mathrm{~A}^{23}$ in $p 53^{-1-}$ mice (Fig. $6 D$ ), showing the $p \mathrm{~S}^{23}$ dependent process. Inhibition of Bax by application of BIP-V5 or inhibition of p53 transcriptional activity by application of pifithrin- $\alpha$ partially inhibited PI labeling (Fig. $6 B$ ), suggesting that $p S^{23}$ activates neuronal necrosis via a $B a x$-independent process. To determine a role of CypD in Bax-independent necrosis, we cultured cortical neurons lacking the $C y p D$ gene $\left(\mathrm{CypD}^{-1-}\right.$ cortical neurons). We found that $\mathrm{CypD}^{-1-}$ neurons were largely resistant to the $p S^{23}$-induced PI labeling (Fig. $6 D$ ), although they remained to be vulnerable to TUNEL labeling (Fig. 6D). Thus, CypD is a substrate of $p S^{23}$ for $c D A P K 1-i n d u c e d$ necrosis. Previous studies showed that expression of exogenous p53 was necrotic to cortical neurons. It is likely that p53 shares the similar effects as cDAPK1 for the induction of neuronal necrosis. In line with this idea, we showed that deletion of $C y p D$ gene completely blocked p53-induced PI labeling (Fig. 6E). When Tat-p53DM that interrupts DAPK1-p53 interaction was applied, it protected against cDAPK1, but not p53induced cell death (Fig. 6E). Together, these results revealed that p53 constituted a substrate of DAPK1 for the induction of CypDdependent necrosis and Bax-dependent apoptosis.

\section{DAPK1-p53 interaction mediates OGD injury}

Having determined that the $p \mathrm{~S}^{23}$ acts as a signaling point of convergence of both necrotic and apoptotic pathways of cell death, we next determined whether it is involved in ischemic injuries. We challenged the DAPK $1^{+/+}$and DAPK $1^{-/-}$neurons (DIV14), 

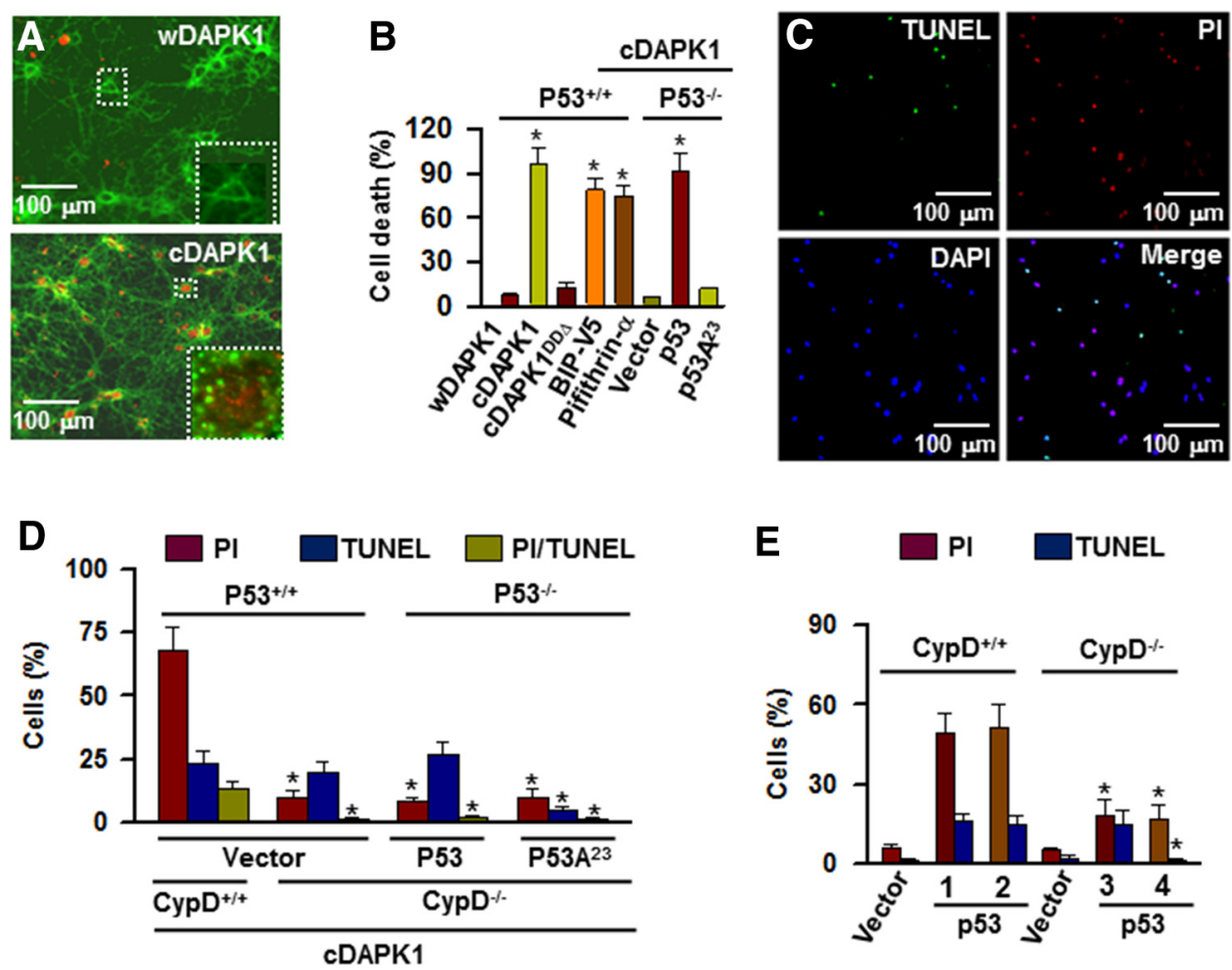

Figure 6. $\quad p S^{23}$-CypD interaction induces neuronal necrosis but not apoptosis. $\boldsymbol{A}, \boldsymbol{B}$, Representative images $(\boldsymbol{A})$ show the PI staining (red) in the cultured mouse cortical neurons expressing either wDAPK1-eGFP or CDAPK1-eGFP (green). Cultured p53 ${ }^{+/+}$cortical neurons (DIV10) were transfected with the rAAV1/2 viral vectors encoding wDAPK1, CDAPK1, CDAPK1 DD $\Delta$ alone, or cDAPK1 in the presence of $10 \mu \mathrm{M}$ BIP-V5, or pifithrin- $\alpha$. In the cultured $p 53^{-1-}$ neurons, CDAPK1 was coexpressed with p53 or p53A ${ }^{23}$. Three days after transfection, the cultures were stained with PI. The death cells are expressed as the percentage of PI in the bar graph $(\boldsymbol{B})$. Data are mean \pm SEM. ${ }^{*} p<0.01 . n=5 /$ group. $\boldsymbol{C}, \boldsymbol{D}$, Representative images $(\boldsymbol{C})$ show double labeling of the cultured cortical neurons with PI and TUNEL. The labeling was performed $3 \mathrm{~d}$ after expression of cDAPK1. D, Bar graph represents percentage of PI- or TUNEL-labeled cells versus DAPI. Data are mean \pm SEM $(n=5$ experiments per group). ${ }^{*} p<0.01$. $E$, The induction of neuronal death by expression of exogenous $\mathrm{p} 53$ is independent of the DAPK1-p53 interaction. Cultured CypD ${ }^{+/+}$and CypD ${ }^{-1-}$ neurons were expressed with an empty vector or p53 in the presence of $5 \mu \mathrm{m}$ Tat-p53DM (bar 1), Tat-s-p53DM (bar 2), or vehicle (bar 3) or BIP-V5 (bar 4). Data are mean \pm SEM. ${ }^{*} p<0.01 . n=5 /$ group.

in which wild-type p53 or its mutant $\mathrm{p} 53 \mathrm{~A}^{23}$ was reconstituted, with OGD for 60 or $90 \mathrm{~min}$. OGD is widely considered an in vitro cellular model of ischemic stroke (Tu et al., 2010). At 24, 30, 36, or $48 \mathrm{~h}$ after $60 \mathrm{~min}$ OGD treatment, the cultures were used for the measurement of $p S^{23}$ accumulation. We found that $p S^{23}$ level increased $24 \mathrm{~h}$ after OGD challenge and peaked at $48 \mathrm{~h}$ later. $p \mathrm{~S}^{23}$ accumulation was observed in DAPK $1^{+/+}$, but not in DAPK $1^{-1-}$, cells (Fig. $7 A, B$ ) and was associated with no change in p53 mRNA (Fig. 7C) and protein levels (data are not shown). Thus, OGD challenge activated DAPK1 and in turn causes $p \mathrm{~S}^{23}$, but not p53, expression in the cultured cortical neurons. After $p \mathrm{~S}^{23}$ expression, the cultures were stained with PI together with TUNEL (Fig. $7 \mathrm{D}, E$ ). In case of $60 \mathrm{~min}$ OGD, $46 \%$ cells were necrotic, according to PI labeling and $21 \%$ cells were apoptotic, according to TUNEL labeling (Fig. $7 F$ ). When the cultured cells were challenged with 90 min OGD, 89\% cells were labeled with PI and $18 \%$ cells were labeled with TUNEL (Fig. $7 F$ ), showing that the majority of cells were killed by OGD challenge. Pretreatment of the cultures with $10 \mu \mathrm{M}$ Tat-p53DM effectively protected the cultures from PI and TUNEL labeling (Fig. $7 F$ ). The similar protection from OGD injury was observed in the cultured $\mathrm{p} 53^{-1-}$ neurons (Fig. $7 D-F)$. Thus, the DAPK1-p53 interaction was indispensable for both cell necrosis and apoptosis in ischemic insults.

\section{Discussion}

In the present study, we showed that activated DAPK1 catalyzes p53 into $p S^{23}$ via a direct binding of DAPK1DD to p53DM. We demonstrated that $p S^{23}$ represents a functional mode of $\mathrm{p} 53$, essential for both transcription-dependent and -independent pathways of apoptosis and necrosis. We also revealed that a small membrane-permeable peptide inhibitor (Tat-p53DM) effectively intercepted the DAPK1-p53 interaction in the cortical neurons. Thus, our present study has not only uncovered a core cell death signaling complex that merges the dual pathways of brain cell death in ischemia but also identified a desirable cell death inhibitor against ischemic injuries.

The p53 protein plays a role in several modes of cell death depending in part upon its subcellular distributions (Meulmeester and Jochemsen, 2008; Brady et al., 2011; Vaseva et al., 2012). In the nucleus, p53 is a crucial transcriptional regulator and controls the program of transcription-dependent apoptosis in response to various signals, including DNA damage, oxidative stress, and ischemia (Meulmeester and Jochemsen, 2008). The main actions of p53 in cell apoptosis involve transcriptional induction of proapoptotic genes, such as Bax, Puma, and Noxa, that in turn trigger mitochondrial pathways, including Cyto- $c$ release and Casp3 accumulation (Green and Kroemer, 2009). Recently, it was shown that, after stress, the cytoplasmic pool of $\mathrm{p} 53$ rapidly relocates onto the mitochondrial surface, where it physically interacts with proapoptotic Bcl2 family members, leading to PTP opening and apoptosis (Mihara et al., 2003). Our present study demonstrated that p53 can be phosphorylated at serine-23 through a direct binding of activated DAPK1 to p53DM. The experiments with reconstitution of wild-type p53 or its mutant $\mathrm{p} 3 \mathrm{~A}^{23}$ in $\mathrm{p} 53^{-1-}$ neurons revealed that $p \mathrm{~S}^{23}$ represents a func- 
A

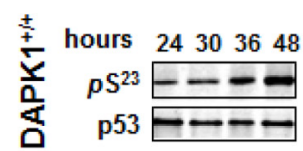

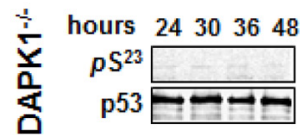

B

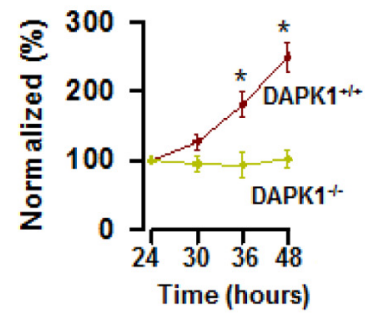

C

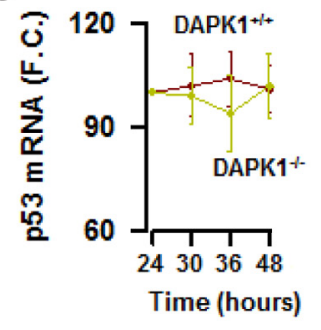

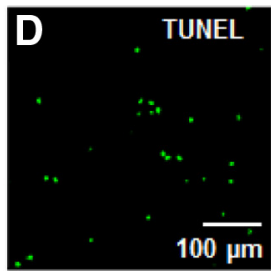
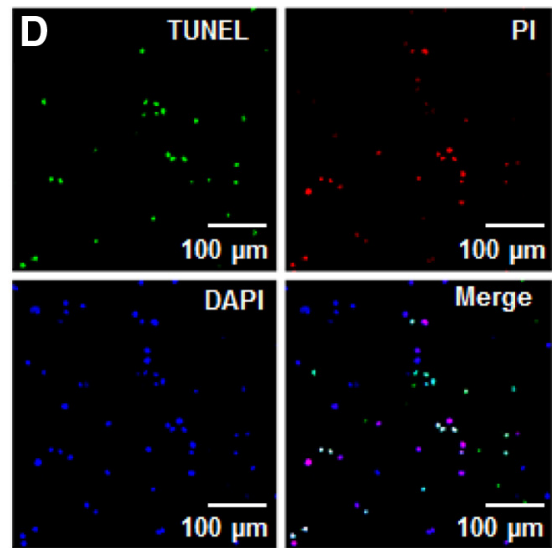
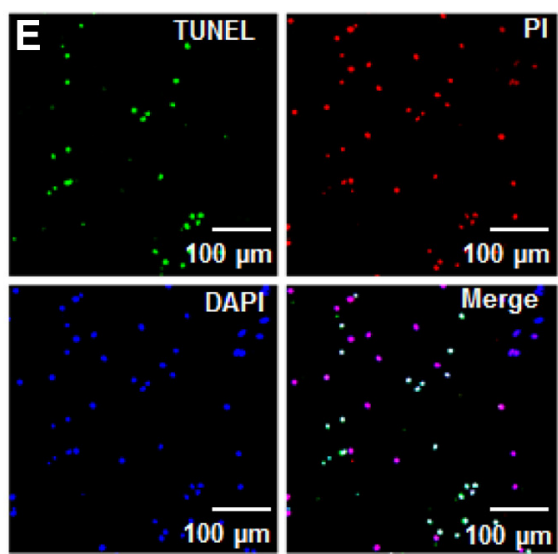

F $\square 60 \min$

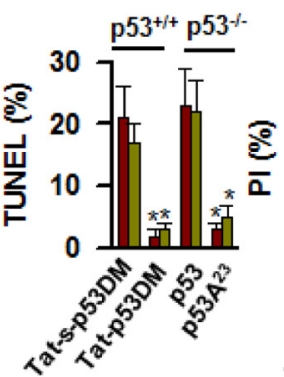

$90 \mathrm{~min}$

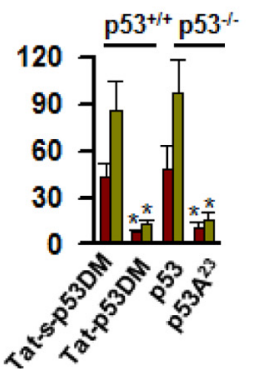

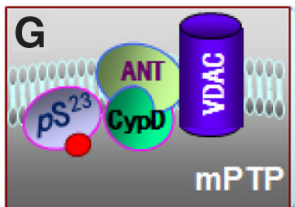

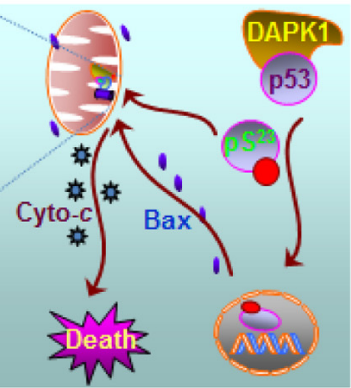

Figure 7. The DAPK1-p53 interaction mediates ischemic neuronal death. $A, 0$ GD induces $p S^{23}$ accumulation via DAPK1 activation. Cultured DAPK1 ${ }^{+/+}$and DAPK $1^{-1-}$ mouse cortical neurons (DIV14) were treated with $60 \mathrm{~min} 0 \mathrm{GD}$. At 24,30,36, or $48 \mathrm{~h}$ after $0 \mathrm{GD}$ treatment, cellular extracts were prepared and blotted with anti-p $\mathrm{S}^{23}$ and anti-p53 antibodies. $\boldsymbol{B}$, The ratio of $p S^{23}$ versus p53 was normalized at different time points to the $24 \mathrm{~h}$ time point (defined as $100 \%)$. Data are mean \pm SEM $\left(n=4\right.$ assays). ${ }^{*} p<0.01 . C, 0 G D$ does not alter p53 expression. Cultured DAPK $1^{+/+}$and DAPK1 ${ }^{-/-}$cortical neurons (DIV14) were challenged with $60 \mathrm{~min}$ OGD. At 24,30,36, or $48 \mathrm{~h}$ after OGD, cellular RNAs were prepared and analyzed by qPCR. Data are mean \pm SEM ( $n=4$ assays). $\boldsymbol{D}, \boldsymbol{E}$, Representative images showing the double labeling of Pl and TUNEL in cultured cortical neurons treated with $60 \mathrm{~min}$ (D) or $90 \mathrm{~min}(E)$ OGD. Cortical cultures (DIV14) were exposed to 0 GD for $60 \mathrm{~min}$ or 90 min. Three days after recovery from the $0 \mathrm{GD}$ treatment, the cultures werestained with PI (red) and TUNEL (green), as indicated. $\boldsymbol{F}$, The DAPK1-p53 interaction mediates OGD-induced necrosis and apoptosis. Cultured p53 ${ }^{+/+}$neurons were challenged with OGD in the presence of $5 \mu \mathrm{m}$ vehicle, Tat-p53DM, or Tat-s-p53DM. At $3 \mathrm{~d}$ after $0 \mathrm{GD}$, the cultures were stained with PI and TUNEL. In cultured p53 ${ }^{-1-}$ neurons, exogenous wild-type p53 or its mutant p53A ${ }^{23}$ or empty vector was expressed. Data are expressed as a percentage of PI- and TUNEL-labeled cells relative to DAPI labeled cells. Data are mean \pm SEM $\left(n=5\right.$ assays). ${ }^{*} p<0.01$. G, A working model: the DAPK1-p53 interaction activates necrotic and apoptotic pathways of ischemic injury through transcription-and mitochondria-dependent pathways. DAPK1 binds to p53DM and catalyzes the $p 5^{23}$, which enters into the nucleus and activates the proapoptotic gene expression and apoptosis. The $p 5^{23}$ also enters into the mitochondrial matrix and interacts with CypD and causes necrosis. ANT, Adenine nucleotide translocase; VDAC, voltage-dependent anion channel; CypD, cyclophilin D; mPTP, mitochondrial permeability transition pore.

tional mode of p53 in the nucleus that activates proapoptotic genes, such as Bax and Puma in cortical cells. Bax is one of the earliest-studied $p 53$ gene targets that interact with mitochondrial proapoptotic signals (Morris et al., 2001; Steckley et al., 2007; Walensky and Gavathiotis, 2011). Consistent with these previous studies, our results showed that the induction of neuronal apoptosis by $p S^{23}$ is completely abolished by deletion of Bax gene or application of a Bax inhibitor, BIP-V5. On the other hand, our data exhibited that $p S^{23}$ is absent in the mitochondrial outer membrane components. Thus, the induction of Bax expression by $p S^{23}$ possibly reflects an essential event for neuronal apoptosis in response to DAPK1 activation.

In our present study, we showed that recruitment of $p S^{23}$ by cDAPK1 into the nucleus activates the mitochondrial PTP- dependent programs of apoptosis. Our data also revealed that PTP activation by $p S^{23}$ is partially affected by deletion of Bax gene or inhibition of Bax via application of BIP-V5. This finding indicates that $p \mathrm{~S}^{23}$ regulates mitochondrial PTP through both Baxdependent and -independent mechanisms. Consistent with this idea, our results demonstrated that $p S^{23}$ is indeed transferred into the inner mitochondrial membrane and interacts with CypD, which is known as a key regulator of mitochondrial PTP (Vaseva et al., 2012).

Through activation of PTP at the inner membrane, CypD controls the programs of cell necrosis via activation of mitochondrial PTP (Baines et al., 2005; Basso et al., 2005; Schinzel et al., 2005). Necrosis is a rapid loss of the cellular membrane potential because of energy depletion and ion pump/channel failure and is 
a central cellular event in ischemia/reperfusion injuries. Earlier studies showed that CypD ${ }^{-1-}$ neurons are resistant to ischemiainduced necrosis in a mouse model of stroke (Vaseva et al., 2012). Of note, these CypD-deficient neurons remain vulnerable to Baxdependent apoptosis. In line with these earlier studies, our data showed that the DAPK1-p53 interaction and subsequent $p S^{23}$ accumulation evoke two functionally distinct mitochondrial death pathways: transcription-dependent Bax expression and transcription-independent $p S^{23}-\mathrm{CypD}$ interaction at the mitochondrial inner membrane, as illustrated in Figure $7 G$.

Our previous studies revealed that DAPK1 is linked to excitatory glutamate receptor channels and becomes activated in response to ischemic insults (Tu et al., 2010). Here, we demonstrated that the signaling events downstream of DAPK1 involve transcription-dependent and -independent pathways through the expression of Bax gene or interaction with CypD in cortical neurons. Accordingly, we synthesized the membrane-permeable peptide Tat-p53DM that showed protective effect against ischemic injury in the cultured cortical neurons in vitro. Necrosis and apoptosis are two distinct mechanisms that mediate ischemic injury in brain cells. Depending on the challenges of the cultured neurons to OGD (60 or 90 min OGD), the percentage of cells undergoing necrosis versus apoptosis varies. In some subsets of cells, we observed some overlap between apoptosis and necrosis ( $\mathrm{TUNEL}^{+} / \mathrm{PI}^{+}$) in response to OGD treatment (Fig. $7 D, E$ ). As interception of DAPK1-p53 interaction effectively blocks these two distinct pathways of neuronal death in ischemia, it is likely to be a preferred therapeutic target for ischemic stroke.

\section{References}

Aarts M, Liu Y, Liu L, Besshoh S, Arundine M, Gurd JW, Wang YT, Salter MW, Tymianski M (2002) Treatment of ischemic brain damage by perturbing NMDA receptor- PSD-95 protein interactions. Science 298:846850. CrossRef Medline

Baines CP, Kaiser RA, Purcell NH, Blair NS, Osinska H, Hambleton MA, Brunskill EW, Sayen MR, Gottlieb RA, Dorn GW, Robbins J, Molkentin JD (2005) Loss of cyclophilin D reveals a critical role for mitochondrial permeability transition in cell death. Nature 434:658-662. CrossRef Medline

Basso E, Fante L, Fowlkes J, Petronilli V, Forte MA, Bernardi P (2005) Properties of the permeability transition pore in mitochondria devoid of $\mathrm{Cy}$ clophilin D. J Biol Chem 280:18558-18561. CrossRef Medline

Bialik S, Kimchi A (2006) The death-associated protein kinases: structure, function, and beyond. Annu Rev Biochem 75:189-210. CrossRef Medline

Brady CA, Jiang D, Mello SS, Johnson TM, Jarvis LA, Kozak MM, Kenzelmann Broz D, Basak S, Park EJ, McLaughlin ME, Karnezis AN, Attardi LD (2011) Distinct p53 transcriptional programs dictate acute DNA-damage responses and tumor suppression. Cell 145:571-583. CrossRef Medline

Brennan AM, Suh SW, Won SJ, Narasimhan P, Kauppinen TM, Lee H, Edling $\mathrm{Y}$, Chan PH, Swanson RA (2009) NADPH oxidase is the primary source of superoxide induced by NMDA receptor activation. Nat Neurosci 12: 857-863. CrossRef Medline

Brochier C, Dennis G, Rivieccio MA, McLaughlin K, Coppola G, Ratan RR, Langley B (2013) Specific acetylation of p53 by HDAC inhibition prevents DNA damage-induced apoptosis in neurons. J Neurosci 33:86218632. CrossRef Medline

Chan PH (2001) Reactive oxygen radicals in signaling and damage in the ischemic brain. J Cereb Blood Flow Metab 21:2-14. Medline

Cheung EC, McBride HM, Slack RS (2007) Mitochondrial dynamics in the regulation of neuronal cell death. Apoptosis 212:979-992. CrossRef Medline

Copani A, Uberti D, Sortino MA, Bruno V, Nicoletti F, Memo M (2001) Activation of cell-cycle-associated proteins in neuronal death: a mandatory or dispensable path? Trends Neurosci 24:25-31. CrossRef Medline

Craig AL, Chrystal JA, Fraser JA, Sphyris N, Lin Y, Harrison BJ, Scott MT, Dornreiter I, Hupp TR (2007) The MDM2 ubiquitination signal in the DNAbinding domain of $\mathrm{p} 53$ forms a docking site for calcium calmodulin kinase superfamily members. Mol Cell Biol 27:3542-3555. CrossRef Medline

Ginsberg MD (2009) Current status of neuroprotection for cerebral ischemia: synoptic overview. Stroke 40:S111-S114. CrossRef Medline
Green DR, Kroemer G (2009) Cytoplasmic functions of the tumor suppressor p53. Nature 458:1127-1130. CrossRef Medline

Hardingham GE, Bading H (2010) Synaptic versus extrasynaptic NMDA receptor signaling: implications for neurodegenerative disorders. Nat Rev Neurosci 11:682-696. CrossRef Medline

Jordán J, Galindo MF, Prehn JH, Weichselbaum RR, Beckett M, Ghadge GD, Roos RP, Leiden JM, Miller RJ (1997) p53 expression induces apoptosis in hippocampal pyramidal neuron culture. J Neurosci 17:1397-1405. Medline

Lipton P (1999) Ischemic cell death in brain neurons. Physiol Rev 79:14311568. Medline

Lipton SA, Rosenberg PA (1994) Excitatory amino acids as a final common pathway for neurologic disorders. N Engl J Med 330:613-622. CrossRef Medline

Lo EH, Moskowitz MA, Jacobs TP (2005) Exciting, radical, suicidal: how brain cells die after stroke. Stroke 36:189-192. CrossRef Medline

Maiuri MC, Tasdemir E, Criollo A, Morselli E, Vicencio JM, Carnuccio R, Kroemer G (2009) Control of autophagy by oncogenes and tumor suppressor genes. Cell Death Differ 16:87-93. CrossRef Medline

Meulmeester E, Jochemsen AG (2008) p53: a guide to apoptosis. Curr Cancer Drug Targets 8:87-97. CrossRef Medline

Mihara M, Erster S, Zaika A, Petrenko O, Chittenden T, Pancoska P, Moll UM (2003) p53 has a direct apoptogenic role at mitochondria. Mol Cell 11: 577-590. CrossRef Medline

Morris EJ, Keramaris E, Rideout HJ, Slack RS, Dyson NJ, Stefanis L, Park DS (2001) Cyclin-dependent kinases and P53 pathways are activated independently and mediate Bax activation in neurons after DNA damage. J Neurosci 477:97-110. Medline

Moskowitz MA, Lo EH, Iadecola C (2010) The science of stroke: mechanisms in search of treatments. Neuron 29:181-198. CrossRef Medline

Raveh T, Berissi H, Eisenstein M, Spivak T, Kimchi A (2000) A functional genetic screen identifies regions at the $\mathrm{C}$-terminal tail and death-domain of death-associated protein kinase that are critical for its proapoptotic activity. Proc Natl Acad Sci U S A 97:1572-1577. CrossRef Medline

Schinzel AC, Takeuchi O, Huang Z, Fisher JK, Zhou Z, Rubens J, Hetz C, Danial NN, Moskowitz MA, Korsmeyer SJ (2005) Cyclophilin D is a component of mitochondrial permeability transition and mediates neuronal cell death after focal cerebral ischemia. Proc Natl Acad Sci U S A 102:12005-12010. CrossRef Medline

Slack RS, Belliveau DJ, Rosenberg M, Atwal J, Lochmüller H, Aloyz R, Haghighi A, Lach B, Seth P, Cooper E, Miller FD (1996) Adenovirusmediated gene transfer of the tumor suppressor, p53, induces apoptosis in postmitotic neurons. J Cell Biol 135:1085-1096. CrossRef Medline

Steckley D, Karajgikar M, Dale LB, Fuerth B, Swan P, Drummond-Main C, Poulter MO, Ferguson SS, Strasser A, Cregan SP (2007) Puma is a dominant regulator of oxidative stress induced Bax activation and neuronal apoptosis. J Neurosci 27:12989-12999. CrossRef Medline

Tu W, Xu X, Peng L, Zhong X, Zhang W, Soundarapandian MM, Balel C, Wang M, Jia N, Zhang W, Lew F, Chan SL, Chen Y, Lu Y (2010) DAPK1 interaction with NMDA receptor NR2B subunits mediates brain damage in stroke. Cell 140:222-234. CrossRef Medline

Uo T, Kinoshita Y, Morrison RS (2007) Apoptotic actions of p53 require transcriptional activation of PUMA and do not involve a direct mitochondrial/cytoplasmic site of action in postnatal cortical neurons. J Neurosci 27:12198-12210. CrossRef Medline

Van Eldik LJ (2002) Structure and enzymology of a death-associated protein kinase. Trends Pharmacol Sci 23:302-304. CrossRef Medline

Vaseva AV, Marchenko ND, Ji K, Tsirka SE, Holzmann S, Moll UM (2012) p53 opens the mitochondrial permeability transition pore to trigger necrosis. Cell 149:1536-1548. CrossRef Medline

Walensky LD, Gavathiotis E (2011) BAX unleashed: the biochemical transformation of an inactive cytosolic monomer into a toxic mitochondrial pore. Trends Biochem Sci 36:642-652. CrossRef Medline

Xiang H, Hochman DW, Saya H, Fujiwara T, Schwartzkroin PA, Morrison RS (1996) Evidence for p53-mediated modulation of neuronal viability. J Neurosci 16:6753-6765. Medline

Yang Y, Shu X, Liu D, Shang Y, Wu Y, Pei L, Xu X, Tian Q, Zhang J, Qian K, Wang YX, Petralia RS, Tu W, Zhu LQ, Wang JZ, Lu Y (2012) EPAC null mutation impairs learning and social interactions via aberrant regulation of miR-124 and Zif268 translation. Neuron 73:774-788. CrossRef Medline

Yuan J (2009) Neuroprotective strategies targeting apoptotic and necrotic cell death for stroke. Apoptosis 14:469-477. CrossRef Medline 